\title{
Sensitivity Study of Advection and Diffusion Coefficients in a Two-Dimensional Stratospheric Model Using Excess Carbon 14 Data
}

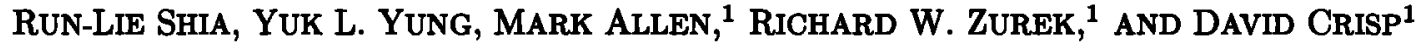 \\ Division of Geological and Planetary Sciences, California Institute of Technology, Pasadena
}

\begin{abstract}
Using the California Institute of Technology/Jet Propulsion Laboratory two-dimensional transport model, with transport coefficients taken from Yang and Tung (1989), we study the time evolution of excess carbon 14 in the stratosphere and the troposphere from October, 1963 to December, 1966. The model provides a satisfactory simulation of the observed data. Due to the impulsive nature of its source, initial distributions of excess carbon 14 exhibit large spatial gradients. This permits important constraints on the range of transport coefficients in the lower stratosphere to be derived. The standard model uses the circulation and eddy diffusivity of the year 1980. Large deviations (by factor of 2) from this standard transport are ruled out by our model. A self-consistently derived $K_{y y}$ which is small $\left(\sim 10^{9} \mathrm{~cm}^{2} \mathrm{~s}^{-1}\right)$ in tropical regions, but is larger $\left(\sim 10^{10} \mathrm{~cm}^{2} \mathrm{~s}^{-1}\right)$ at higher latitudes is preferred. $A \mathrm{~K}_{\mathrm{zz}}$ as large as $1 \times 10^{4} \mathrm{~cm}^{2} \mathrm{~s}^{-1}$ would be inconsistent with the data. Excess carbon 14 is removed from the atmosphere with surface deposition velocities $v_{S}=3 \times 10^{-3} \mathrm{~cm} \mathrm{~s}^{-1}$ and $v_{N}=5 \times 10^{-3} \mathrm{~cm} \mathrm{~s}^{-1}$ in the southern and northern hemispheres, respectively. The last result is contrary to the current understanding that the oceans are the dominant sink for excess ${ }^{14} \mathrm{C}$.
\end{abstract}

\section{INTRODUCTION}

Excess carbon 14 in the stratosphere, collected during the period 1963-1966, has been used by Johnston et al. [1976] to calibrate one-dimensional models of the stratosphere. Therefore, it is natural to ask whether this data set is also useful for testing the transport coefficients in two-dimensional models. Recently, H. Johnston (Use of excess carbon 14 data to test two-dimensional stratospheric models, submitted to Journal of Geophysical Research, 1988; hereinafter Johnston (1988)) advocated the usefulness of this exercise, and carried through considerable data processing to make the data convenient for use in a two-dimensional model. Figure 1 presents Johnston's (1988) initial data in October, 1963 in pressure coordinates (Johnston used altitude). This is several months after the last nuclear bomb test, so that the excess ${ }^{14} \mathrm{C}$ has attained approximate zonal symmetry. Subsequently, the evolution of excess ${ }^{14} \mathrm{C}$ was documented at $70^{\circ} \mathrm{N}, 31^{\circ} \mathrm{N}, 9^{\circ} \mathrm{N}$, and $42^{\circ} \mathrm{S}$ for several years until July, 1966, with data extending to about $30 \mathrm{~km}$. We must emphasize that there are no data above $33 \mathrm{~km}$ or southward of $42^{\circ} \mathrm{S}$. Hence, much of Figure 1 consists of "handdrawn data", which are marked by dashed lines. The units used for the contours in the figure are $10^{5}{ }^{14} \mathrm{C}$ atoms per gram of dry air. These numbers multiplied by $4.82 \times 10^{-18}$ give the volume mixing ratio of ${ }^{14} \mathrm{C}$. Thus the maximum mixing ratio of ${ }^{14} \mathrm{C}$ in the stratosphere is $5.9 \times 10^{-15}$, and the maximum column abundance (from the ground to $56 \mathrm{~km}$ ) is $2.3 \times 10^{10}$ atoms cm${ }^{-2}$. The purpose of this paper is to use the California Institute of Technology/Jet Propulsion Laboratory (Caltech/JPL) two-dimensional model of the strato-

\footnotetext{
${ }^{1}$ Also at Earth and Space Sciences Division, Jet Propulsion Laboratory, California Institute of Technology, Pasadena, California.
}

Copyright 1989 by the American Geophysical Union.

Paper number 89JD00796.

0148-0227/89/89JD-00796\$05.00 sphere to simulate the transport history of excess ${ }^{14} \mathrm{C}$, using Figure 1 as the initial distribution.

There are three essential components of transport in "modern" two-dimensional stratospheric models [Garcia and Solomon, 1983; Guthrie et al., 1984; Ko et al., 1985; Stordal et al., 1985; Holton, 1986; Tung and Yang, 1988]. First is the Brewer-Dobson circulation, which consists of upwelling at the equatorial tropopause and descending motion at high latitudes [Brewer, 1949; Dobson, 1956]. Second is the horizontal eddy diffusivity $K_{y y}$. The third component is the summer-pole to winter-pole Leovy circulation in the upper stratosphere and mesosphere [Leovy, 1964]. Vertical eddy diffusivity, $K_{z z}$, which plays a fundamental role as the only transport process in one-dimensional models, is not believed to be important in the bulk of the stratosphere. It is the triumph of this new generation of two-dimensional models to be able to account for the observed vertical, latitudinal, and seasonal distributions of source molecules such as $\mathrm{N}_{2} \mathrm{O}$, $\mathrm{CH}_{4}, \mathrm{CFCl}_{3}$, and $\mathrm{CF}_{2} \mathrm{Cl}_{2}$, as well as photochemically produced species such as $\mathrm{O}_{3}$ (see World Meteorological Organization (WMO) [1985] for detailed comparison between theory and data). Indeed, there is sufficient confidence in the transport properties of the model that the discrepancy between observed and computed $\mathrm{NO}_{\mathrm{y}}$ led to the postulation of a new $\mathrm{NO}_{\mathrm{y}}$ source in the equatorial lower stratosphere [Ko et al., 1986].

What then is unique about excess ${ }^{14} \mathrm{C}$, and how can it lead to a refinement of the transport component of a two dimensional model? First, excess ${ }^{14} \mathrm{C}\left(\right.$ as $\left.{ }^{14} \mathrm{CO}_{2}\right)$ is a chemically inert tracer in the stratosphere. Its distribution, once we set the initial conditions using observations, is governed only by transport. There are no uncertainties due to chemical production or loss. Second, the source of excess ${ }^{14} \mathrm{C}$ is impulsive rather than quasi-steady. The ultimate disappearance of this radioactive material from the stratosphere provides an absolute calibration for mass exchange between the stratosphere and the troposphere. In fact, it was the study of the dissipation of stratospheric radioactive debris that first yielded estimates of the rate of mass exchange between the troposphere and the middle atmosphere [Reed and 


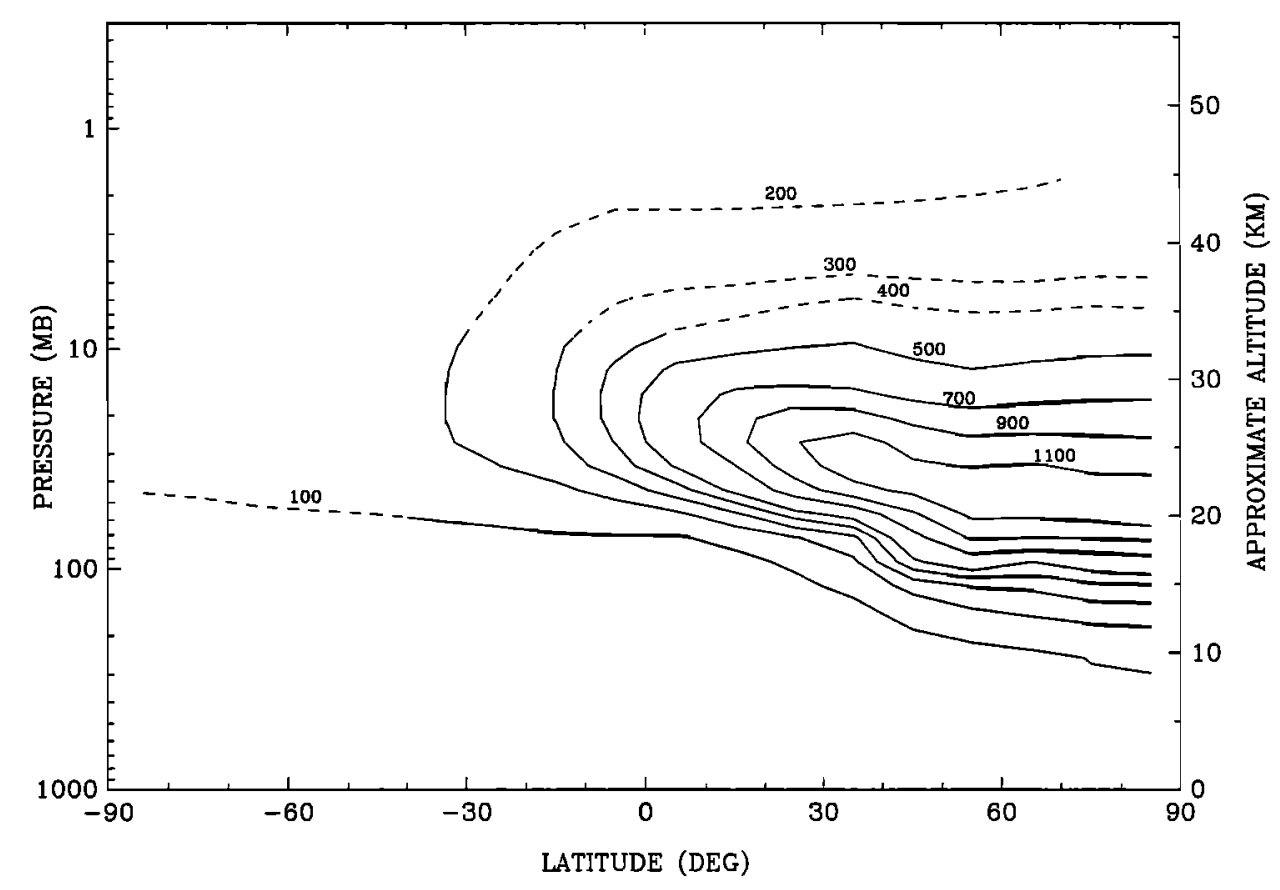

Fig. 1. Initial ${ }^{14} \mathrm{C}$ distribution in October, 1963 taken from Johnston (1988) and interpolated to our pressure coordinates. The units are in $10^{5}{ }^{14} \mathrm{C}$ atoms per gram of $\mathrm{dry}$ air. To convert to ${ }^{14} \mathrm{C}$ volume mixing ratios, the numbers must be multiplied by $4.82 \times 10^{-18}$. The dashed lines are not based on measured data (see text).

German, 1965; Mahlman, 1965; List and Telegadas, 1969; Reiter, 1975].

The advantages of excess ${ }^{14} \mathrm{C}$ as a tracer may be appreciated if we compare it with other chemically produced, downward transported species such as $\mathrm{NO}_{y}$ and $\mathrm{O}_{3}$. The ultimate source of $\mathrm{NO}_{y}$ is upwelling of tropospheric $\mathrm{N}_{2} \mathrm{O}$, and the primary stratospheric sink of $\mathrm{NO}_{\mathrm{y}}$ is downward flow into the troposphere. Thus the source and sink are related to the same circulation. Hence, the abundance of $\mathrm{NO}_{\mathrm{y}}$ in the stratosphere would be rather insensitive to the exact strength of the Brewer-Dobson circulation. As for $\mathrm{O}_{3}, 99 \%$ of it is produced and destroyed chemically in the stratosphere. The observed distribution is the consequence of a competition between chemistry and transport. Given the current uncertainties in the chemistry of $\mathrm{O}_{3}$ (see for example Froidevaux et al. [1985]), it is hard to see how $\mathrm{O}_{3}$ can be considered a well-defined tracer. In other words, even complete agreement between model results and observations may be due to a fortuitous cancellation of errors between chemistry and dynamics.

A third advantage in using excess ${ }^{14} \mathrm{C}$ is that, due to its impulsive nature, excess ${ }^{14} \mathrm{C}$ has very steep initial spatial gradients. In October, 1963 near the peak at midlatitudes, the mixing ratio decreases in the vertical by more than a factor of two per atmospheric scale height away from the peak. At this time there is also a large gradient in the horizontal dimension. The column densities above $10 \mathrm{~km}$ at the north pole, equator, and south pole are in the ratio 10:3:1.3 (see Figure 9). Thus, the degree of latitudinal contrast in the northern hemisphere is between those of $\mathrm{O}_{3}$ and $\mathrm{HNO}_{3}$ [Ko et al., 1985], but the interhemisphere asymmetry is unique. Such large gradients would allow us to explore the sensitivity of our transport model to values of $K_{y y}$ and $K_{z z}$, especially in the lower stratosphere. The fact that our numerical scheme has very little dispersion gives us confidence in the values of the eddy diffusion coefficients thus derived [Prather, 1986; R.-L. Shia et al., Two-dimensional atmospheric transport and chemistry model: Numerical experiments with a new advection algorithm, submitted to Journal of Geophysical Research, 1988 (hereinafter Shia et al., (1988))]. Unfortunately, we can learn almost nothing about transport in the upper stratosphere due to the limited altitude of the data base (mostly confined to below $30 \mathrm{~km}$ ). Also, most of the steep gradients have disappeared after the first six months so that we cannot derive any useful information on $K_{y y}$ and $K_{z z}$ after this time.

For our first attempt to reproduce the excess ${ }^{14} \mathrm{C}$ distribution, for the period from October, 1963 to July, 1966, we use the transport coefficients of Yang and Tung [1989]. The authors diagnostically calculated the diabatic circulation from the National Meteorological Center (NMC) temperature field and self-consistently determined the isentropic mixing coefficients by solving the momentum equation (see discussion in next section). These transport coefficients have been successfully used to simulate $\mathrm{O}_{3}$ distribution. A number of runs will be made to test the sensitivity of our results to variations in advection and horizontal eddy diffusivity $\left(K_{y y}\right)$. Upper limits on $K_{z z}$ can be set. Finally, the interaction between ${ }^{14} \mathrm{C}$ and the surface will be explored in our model. As we shall see, our major contributions will be sensitivity studies of two-dimensional transport modeling in the lower stratosphere. We find that simulation of the removal of excess ${ }^{14} \mathrm{C}$ from the stratosphere requires $\mathrm{K}_{\mathrm{yy}}$ values which are larger in the extratropics than in the tropics, and that $\mathrm{K}_{\mathrm{gz}}<10^{4} \mathrm{~cm}^{2} \mathrm{~s}^{-1}$ in the lower stratosphere. Furthermore, our sensitivity studies indicate that tropospheric removal (at the surface) must be significantly faster in the northern hemisphere than in the south. 


\section{MODEl Description}

The meridional coordinate that has been adopted in the two-dimensional model is $y=a \theta$, where $a$ is planetary radius, and $\theta$ is latitude defined to be $-90^{\circ}$ at the south pole and $90^{\circ}$ at the north pole. For vertical coordinate we choose $z=H \ln \left(p_{s} / p\right)$, where $p$ is pressure, $p_{s}$ is surface pressure, and $H$ is a fixed constant. The constants $p_{s}$ and $H$ are set equal to $1000 \mathrm{mbar}$ and $7 \mathrm{~km}$, respectively, in this paper. We also use the dimensionless coordinate $\xi=z / H$. For the studies reported here, the transport code (Shia et al., 1988) uses a grid having 18 latitudinal boxes from pole to pole, and 32 vertical layers from $z=0$ to $z=56 \mathrm{~km}$. The transport circulation consists of a zonal mean stream function $\psi$ and eddy diffusivities $K_{y y}$ and $K_{z z}$. The two-dimensional model is modular in form, so that the transport circulation can be derived from either observed or modeled (for example, by a general circulation model (GCM)) fields (R. W. Zurek et al., Derivation of the stream function and eddy diffusivity from monthly mean fields of the Geophysical Fluid Dynamics Laboratory stratospheric model within the framework of a two-dimensional model, to be submitted to Journal of Geophysical Research, 1989; hereinafter Zurek et al. (1989)). That circulation can also be independently specified, which is the option taken in this paper.

From the stream function we can readily derive velocities for meridional motion, $v$, and vertical motion, $w$,

$$
\begin{gathered}
v=-\frac{1}{\cos \theta} e^{\xi} \frac{\partial}{\partial z}\left(e^{-\xi} \psi\right) \\
w=\frac{1}{\cos \theta} \frac{\partial \psi}{\partial y}
\end{gathered}
$$

Note that the quantities $\psi, v$, and $w$ refer to the Eulerian residual circulation, and are usually denoted by $\psi^{*}, v^{*}$, and $w^{*}$. However, we drop the asterisks for simplicity. This velocity field $\mathbf{u}=(v, w)$ is non-divergent in the following sense,

$$
e^{\xi} \nabla \cdot\left(e^{-\xi} \mathbf{u}\right)=\frac{1}{\cos \theta} \frac{\partial}{\partial y}(\cos \theta v)+e^{\xi} \frac{\partial}{\partial z}\left(e^{-\xi} w\right)=0
$$

The eddy diffusive fluxes are parameterized by

$$
\begin{aligned}
& F_{y}=-\left(K_{\mathrm{yy}} \frac{\partial \chi}{\partial \mathrm{y}}+\mathrm{K}_{\mathrm{yz}} \frac{\partial \chi}{\partial \mathrm{z}}\right) \\
& F_{z}=-\left(\mathrm{K}_{\mathrm{zy}} \frac{\partial \chi}{\partial \mathrm{y}}+\mathrm{K}_{\mathrm{zx}} \frac{\partial \chi}{\partial \mathrm{z}}\right)
\end{aligned}
$$

where $\chi$ is the mixing ratio of the tracer under consideration. The horizontal eddy diffusivity $K_{y y}$ cannot be arbitrarily specified, but is derived here from the relation

$$
\mathrm{K}_{\mathrm{yy}} \frac{\partial q}{\partial y}=-\nabla \cdot \mathbf{E}
$$

where $q$ is the zonal mean potential vorticity and $\mathbf{E}$ is the Eliassen-Palm flux [Edmon et al., 1980; Tung, 1986, 1987; Plumb and Mahlman, 1987; Newman et al., 1986, 1988]. According to Tung [1982], $\mathrm{K}_{\mathrm{yz}} \cong \mathrm{K}_{\mathrm{zy}} \cong 0$ in isentropic coordinates. However, in transforming from this coordinate to log pressure coordinate (used in our model), $K_{\mathbf{y y}}$ may have a nonzero projection into $K_{\mathbf{y z}}$. The impact of this $K_{\mathbf{y z}}$ derived from coordinate transformation is, however, small due to the small angle of inclination of the isentropes with respect to the isobaric surfaces in the stratosphere, and can therefore be ignored. In our standard model we adopt an arbitrarily small value of $\mathrm{K}_{\mathrm{zz}}=1 \times 10^{2} \mathrm{~cm}^{2} \mathrm{~s}^{-1}$ in the stratosphere.

In the troposphere, the diabatic circulation is not very effective for mass transport. Rather than trying to develop a correct stream function for the troposphere, we choose to parameterize the transport by eddy diffusion. This region of strong diffusive mixing extends to the model tropopause, defined in each month by the minimum $z$ such that,

$$
\frac{d T}{d z}>-2.5 \frac{\mathrm{K}}{\mathrm{km}}
$$

Based on our experience with one-dimensional and threedimensional modeling [Froidevaux et al., 1985; Pinto et al., 1983], we adopt the following values,

$$
\begin{aligned}
K_{z z} & =1 \times 10^{5} \mathrm{~cm}^{2} \mathrm{~s}^{-1} \\
K_{y y} & =1 \times 10^{10} \mathrm{~cm}^{2} \mathrm{~s}^{-1}
\end{aligned}
$$

The continuity equation for the mixing ratio of an inert tracer is

$$
\begin{gathered}
\frac{\partial \chi}{\partial t}+v \frac{\partial \chi}{\partial y}+w \frac{\partial \chi}{\partial z}-\frac{1}{\cos \theta} \frac{\partial}{\partial y}\left\{\cos \theta \mathrm{K}_{\mathrm{yy}} \frac{\partial \chi}{\partial \mathrm{y}}\right\} \\
-e^{\xi} \frac{\partial}{\partial z}\left\{e^{-\xi} \mathrm{K}_{\mathrm{zz}} \frac{\partial \chi}{\partial \mathrm{z}}\right\}=0
\end{gathered}
$$

where the left-hand side of (10), respectively, denotes the time rate of change of $\chi$, the divergence of advective fluxes, and the divergence of diffusive fluxes $\left(F_{i}\right)$. The transport coefficients for each month (the midmonth values) are entered into the tracer model.

Figures $2 a-2 d$ give the mass-weighted stream function, $\Psi_{m}$, for the months of January, April, July, and October. $\Psi_{m}$ is related to $\psi$ by

$$
\Psi_{m}=2 \pi a \rho_{s} e^{-\xi_{\psi}} \psi
$$

where $\rho_{s}$ is the density of air at the ground $\rho_{s}=p_{s} / g H=$ $1.46 \times 10^{-3} \mathrm{~g} \mathrm{~cm}^{-3}$, and $a$ is the radius of the Earth. The stream function (Figure 2), and the associated velocities (Figures 3 and 4), and the horizontal eddy diffusivities $K_{y y}$ (Figure 5) are taken from Yang and Tung [1989] for the year 1980. They are derived from NMC observational analyses of temperature of the troposphere and stratosphere (up to 8 scale heights [see Geller and $W u, 1987$ ]). The data are available from the end of 1978 to the present. The first complete year of data in the series, 1979 , is abnormally active when compared with the climatological mean based on all the years in the series. Data from the second year, 1980, are chosen here because they are more "normal." The diabatic velocities and isentropic mixing coefficients were computed in isentropic coordinates and then transformed to pressure coordinates in the present study. 
(a)

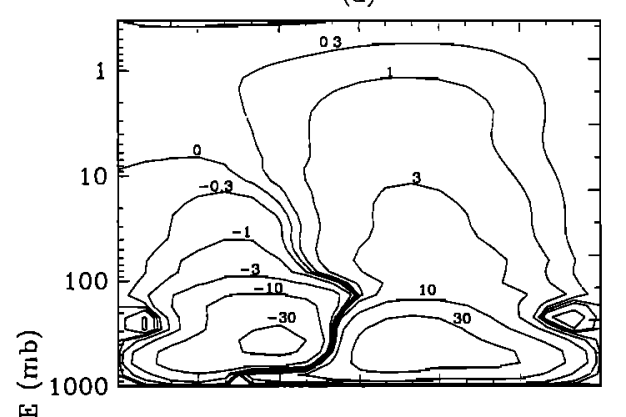

(c)

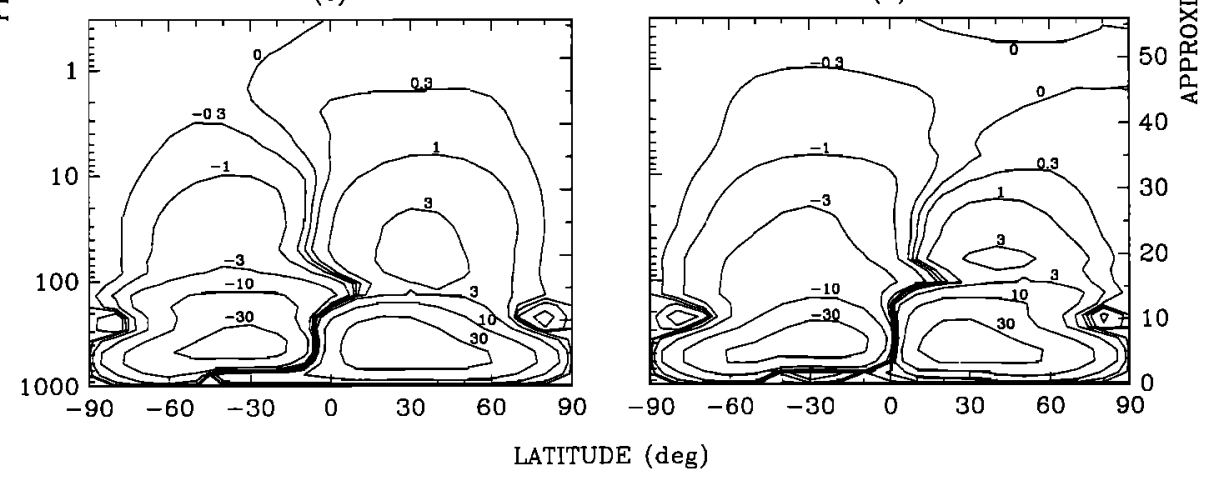

(D)

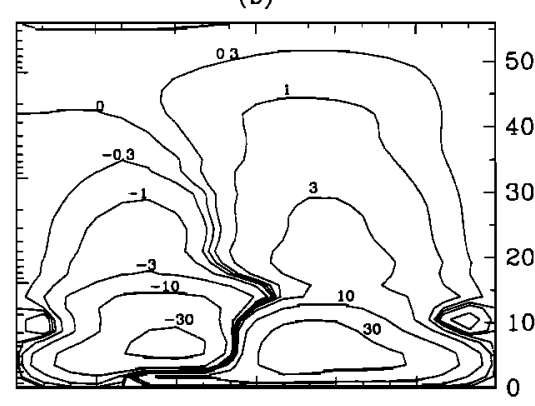

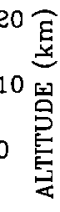

돈

Fig. 2. Mass-weighted stream function $\Psi_{m}$ in units of $10^{12} \mathrm{~g} \mathrm{~s}^{-1}$. (a) January, (b) April, (c) July, (d) October. Positive (negative) values imply clockwise (anticlockwise) flow.

(a)

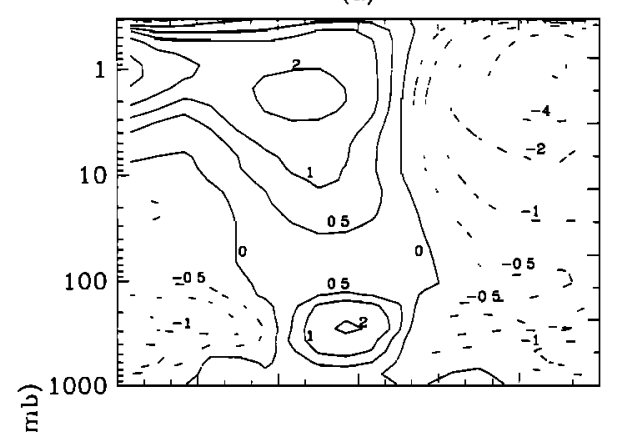

(c)

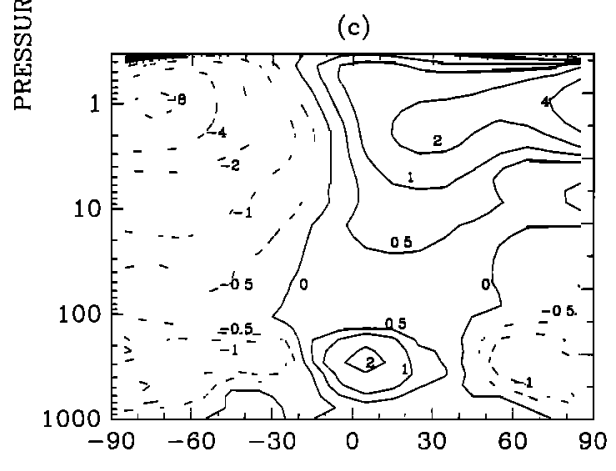

(b)

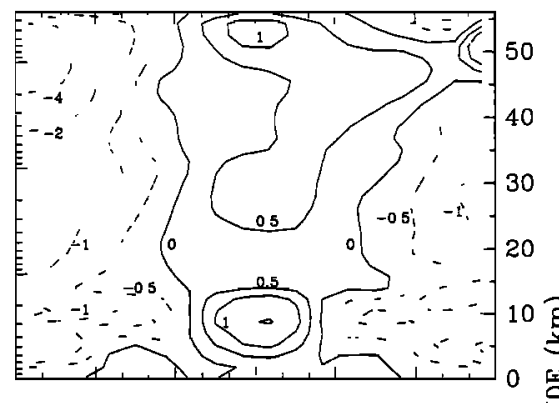

(d)

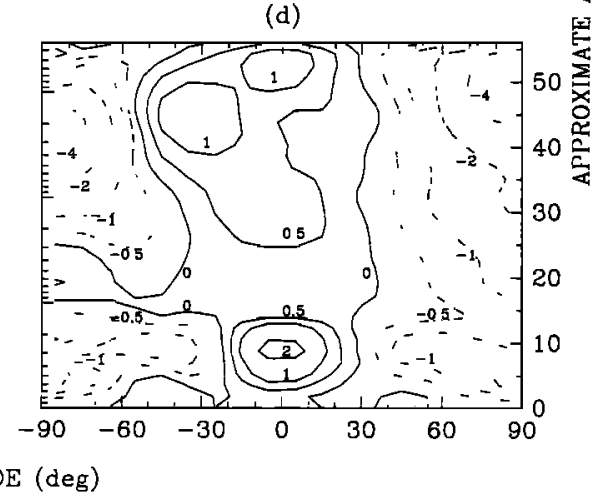

Fig. 3. Vertical velocity $w$ computed for the diabatic circulation. The units are millimeters per second. The dotted lines refer to negative values (downward velocity). (a) January, (b) April, (c) July, (d) October. 
(a)

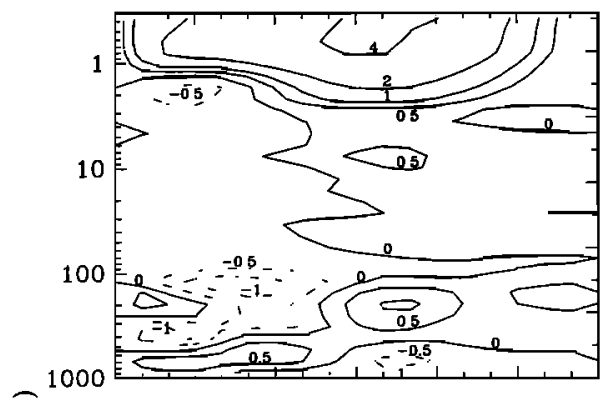

(c)

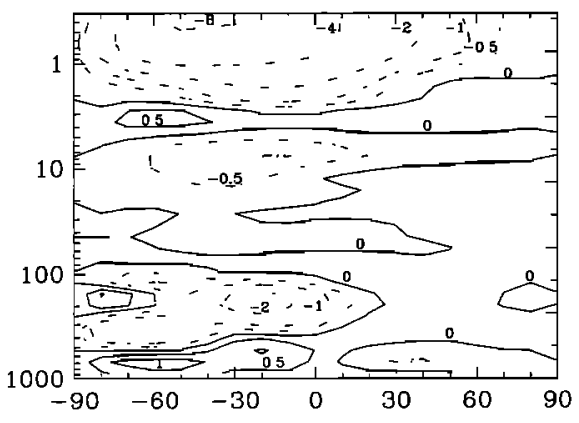

IAATITUDE (deg) (b)

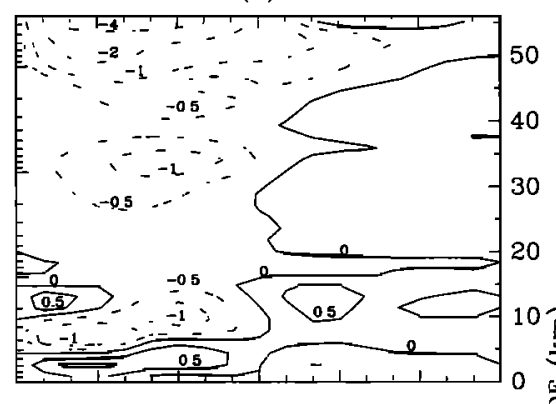

(d)

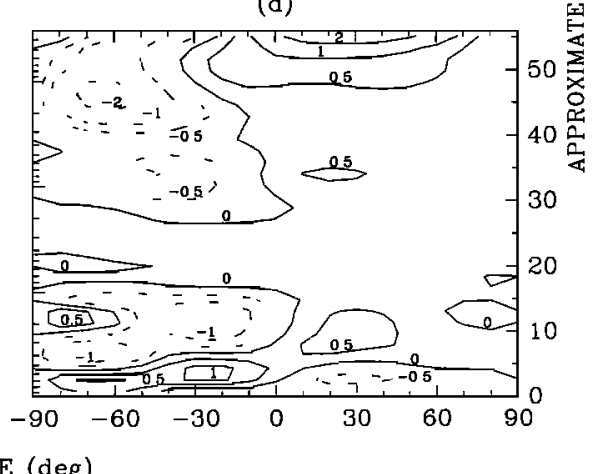

Fig. 4. Same as Figure 3 for meridional velocity $v$ in units of meters per second. (a)

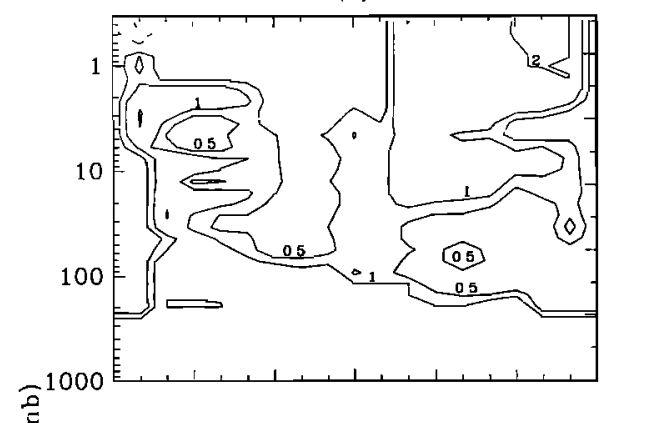

(c)

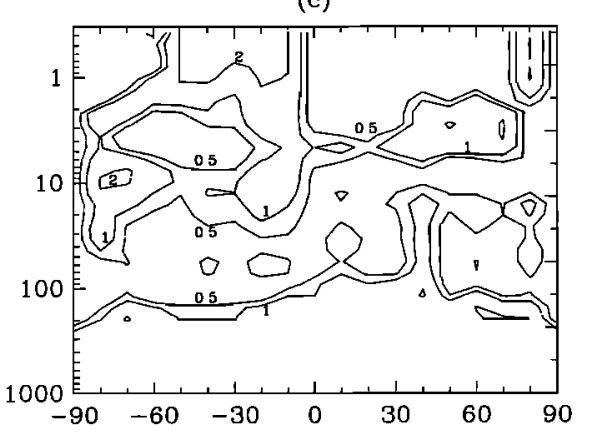

(b)

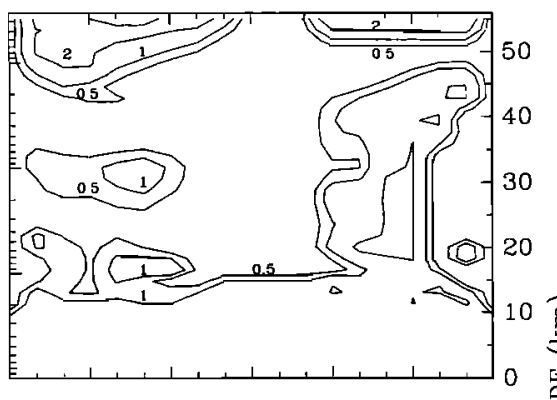

(d)

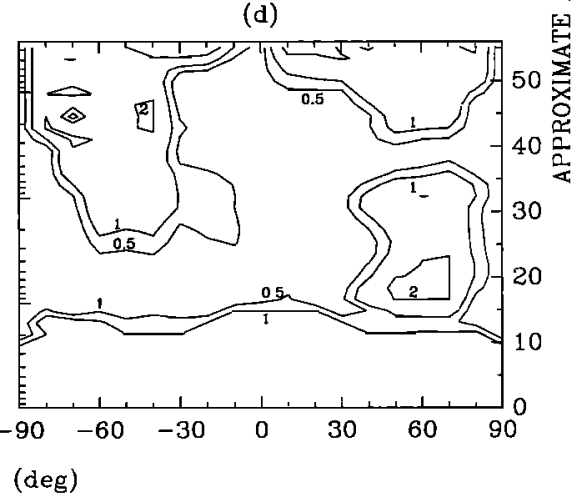

Fig. 5. Same as Figure 3 for $K_{y y}$ in units of $10^{10} \mathrm{~cm}^{2} \mathrm{~s}^{-1}$ computed using conservation of potential vorticity. 
$\Psi_{m}$ has a simple physical meaning: it is the integrated mass flux,

$$
\begin{aligned}
\Psi_{m}(\theta, z) & =-2 \pi a \rho_{s} \cos \theta \int_{0}^{z} e^{-\xi} v d z \\
& =2 \pi a^{2} \rho_{s} e^{-\xi} \int_{-\pi / 2}^{\theta} \cos \theta w d \theta
\end{aligned}
$$

The first expression is the vertically integrated ( 0 to $z$ ) mass flux across latitude $\theta$; the second expression is the horizontally integrated $(-\pi / 2$ to $\theta)$ mass flux across pressure surface $z$. Inspection of Figure 2 suggests that the integrated mass flux in the region of equatorial upwelling is about $9.3 \times 10^{12}$ $\mathrm{g} \mathrm{s}^{-1}$. Since the stratospheric mass above $100 \mathrm{mbar}$ is $5.2 \times 10^{20} \mathrm{~g}$, this implies that the entire stratosphere is ventilated in about 1.8 years in our model. Above $10 \mathrm{mbar}$ $(\sim 30 \mathrm{~km})$, the stream functions clearly reveal the singlecell summer pole to winter pole circulation (Figures $2 a$ and $2 c$ ). Figures $3 a-3 d, 4 a-4 d$, and $5 a-5 d$ show corresponding values of the vertical velocity $w$, meridional velocity $v$, and $K_{y y}$. Figures $3 a-3 d$ show that the upwelling portion of the Brewer-Dobson circulation extends to $\pm 30^{\circ}$ for all seasons. Descending motion at the tropopause occurs at higher latitudes. The horizontal velocities (Figures $4 a-4 d$ ) are related to the vertical velocities through the nondivergence relation (3). Note that the order of magnitude of stratospheric $K_{y y}$ is $10^{10} \mathrm{~cm}^{2} \mathrm{~s}^{-1}$, with characteristic horizontal diffusion time over a planetary radius given by

$$
\tau_{y y}=\frac{a^{2}}{\mathrm{~K}_{y y}}=4.1 \times 10^{7} \mathrm{~s}=1.3 \text { years }
$$

This time scale is comparable to that due to advection. Therefore, we expect both advection and diffusion to be important for tracer transport. There are regions of the atmosphere during certain seasons (Figures $5 a$ and $c$ ) with large negative values of $K_{y y}$. This is due to the breakdown of the approximate relationship (6) between potential vorticity and Eliassen-Palm flux in the upper stratosphere, where gravity waves may become important. Where the computed $\mathrm{K}_{\mathrm{yy}}$ is negative, we replace it by a small positive value $1 \times 10^{8} \mathrm{~cm}^{2}$ $\mathrm{s}^{-1}$. The values of $\mathrm{K}_{\mathrm{zz}}$ are given by a small constant $\left(10^{2}\right.$ $\left.\mathrm{cm}^{2} \mathrm{~s}^{-1}\right)$ above the tropopause, and a larger constant $\left(10^{5}\right.$ $\mathrm{cm}^{2} \mathrm{~s}^{-1}$ ) below the tropopause and are not shown graphically. The essential aspects of our model are summarized in Table 1.
The model was initialized with the distribution of excess ${ }^{14} \mathrm{C}$ as shown in Figure 1. The boundary conditions at the top and at the poles are zero fluxes. After some experimentation, we find a standard deposition velocity at the surface $v_{S}=3 \times 10^{-3} \mathrm{~cm} \mathrm{~s}^{-1}$ for the southern hemisphere, and $v_{N}=5 \times 10^{-3} \mathrm{~cm} \mathrm{~s}^{-1}$ for the northern hemisphere. The choice is close to Liss' [1988] value of $5.6 \times 10^{-3} \mathrm{~cm} \mathrm{~s}^{-1}$ for ${ }^{14} \mathrm{C}$ takeup by oceans (the stated probable error is $25 \%$; for a more detailed discussion see Broecker and Peng [1982]). The sensitivity of our model results to the choice of $v_{S}$ and $v_{N}$ will be discussed later.

Having prescribed the transport coefficients, the initial and the boundary conditions, we solve (10) by marching forward in time using the numerical algorithms described by Prather [1986] and Shia et al. (1988). The time step is 12 hours, and the stream functions and $K_{y y}$ are updated each month, repeating themselves after 12 months. The run is stopped after 3.25 years in December, 1966.

\section{STANDARD MODEL}

The time evolution of the excess ${ }^{14} \mathrm{C}$ cloud in the stratosphere in 1964 as simulated by the standard model is shown in Figures $6 a-6 d$. Initially excess ${ }^{14} \mathrm{C}$ is transported into the southern stratosphere, and later into the upper stratosphere and the troposphere. Note that in October, 1963 (Figure 1) the 300 units contour line barely crosses the equator, but a year later (Figure 6d) it has nearly reached the south pole. By this time the 100 units contour has penetrated into the troposphere at northern high latitudes. Figures $7 a-7 d$ and 8a-8d follow the subsequent evolution in 1965 and 1966 . Motion of material is generally upward near the equator, and downward toward the poles, consistent with the circulation given in Figures 2-4. The effect of $K_{y y}$ in the model is to cause a steady smoothing of the horizontal gradient. To summarize this information more compactly we perform vertical integrals of excess ${ }^{14} \mathrm{C}$ abundance above $10 \mathrm{~km}$. The results, as a function of latitude, for October, 1963 and January 1964-1966, are shown in Figure 9. Note the rapid initial decay of the large horizontal gradient in column excess ${ }^{14} \mathrm{C}$, followed by a slower rate of decay as the distributions become smoother. Toward 1965 and 1966, the column abundances display an equatorial minimum, reminiscent of that for $\mathrm{O}_{3}$. The reason is, of course, common to both phenomena, i.e., equatorial upwelling, as is also evident from Figure 8d. Starting in January, 1966 (Figure 8a), the excess ${ }^{14} \mathrm{C}$ distribution in the lower stratosphere gradually as-

\begin{tabular}{|c|c|}
\hline Model Feature & Specification \\
\hline Grid & $\begin{array}{l}\text { Horizontal coordinate } a \theta \\
\theta \text { from }-85^{\circ} \text { (south pole) to } 85^{\circ} \text { (north pole) in steps of } 10^{\circ} \\
\text { Vertical coordinate } z=H \ln \left(p_{s} / p\right)\left(H=7 \mathrm{~km}, p_{\mathrm{s}}=1000 \mathrm{mbar}\right) \\
\quad z \text { from } 0\left(p=p_{s}\right) \text { to } 56 \mathrm{~km}(p=0.34 \mathrm{mbar}) \text { in steps of } 1.75 \mathrm{~km}\end{array}$ \\
\hline $\begin{array}{l}\text { Tropopause } \\
\text { Advection } \\
\text { Horizontal diffusion }\end{array}$ & $\begin{array}{l}\text { Defined by (7) using GFDL SKYHI GCM data for temperature. } \\
\text { Residual circulation input from Yang and Tung [1989]. Updated every month for middle of the month. } \\
\text { Self-consistent stratospheric } K_{y y} \text { computed using (6) supplied by Yang and Tung [1989]. Updated every } \\
\text { month. Tropospheric } K_{y y}=1 \times 10^{10} \mathrm{~cm}^{2} \mathrm{~s}^{-1} \text {. }\end{array}$ \\
\hline $\begin{array}{l}\text { Vertical diffusion } \\
\text { Boundary conditions }\end{array}$ & $\begin{array}{l}\text { Stratospheric } K_{\mathrm{zz}}=1 \times 10^{2} \mathrm{~cm}^{2} \mathrm{~s}^{-1} \text {. Tropospheric } K_{\mathrm{zz}}=1 \times 10^{5} \mathrm{~cm}^{2} \mathrm{~s}^{-1} \text {. } \\
\text { Zero fluxes at the upper boundary and at the poles. Deposition velocities at the lower boundary } \\
\text { (see Table 3). }\end{array}$ \\
\hline
\end{tabular}

TABLE 1. Summary of the Basic Structure and the Transport Coefficients in the Caltech-JPL Two-Dimensional Model 


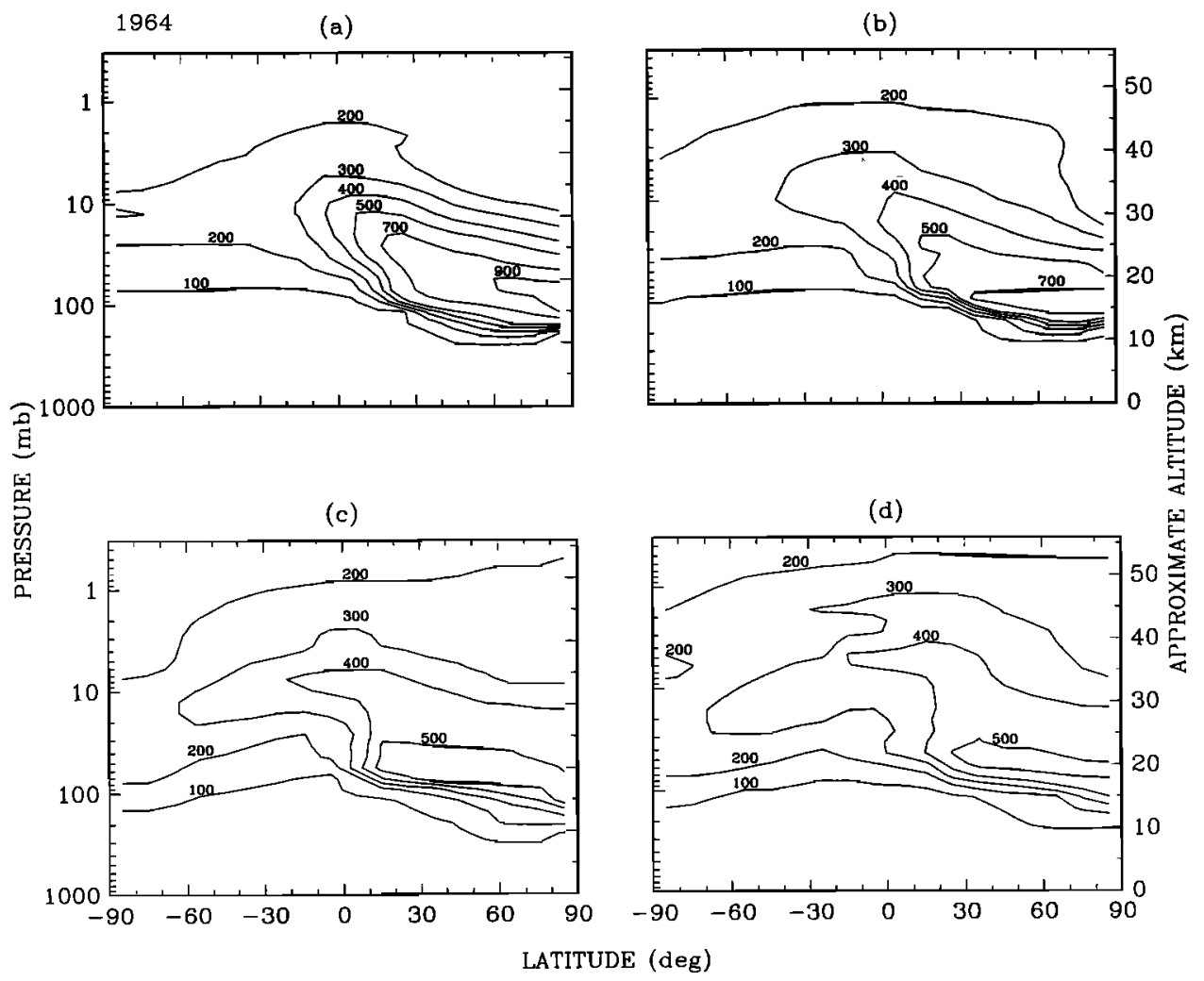

Fig. 6. Contours of excess ${ }^{14} \mathrm{C}$ computed in the standard model in 1964 in the same units as in Figure 1. (a) January, (b) April, (c) July, (d) October.

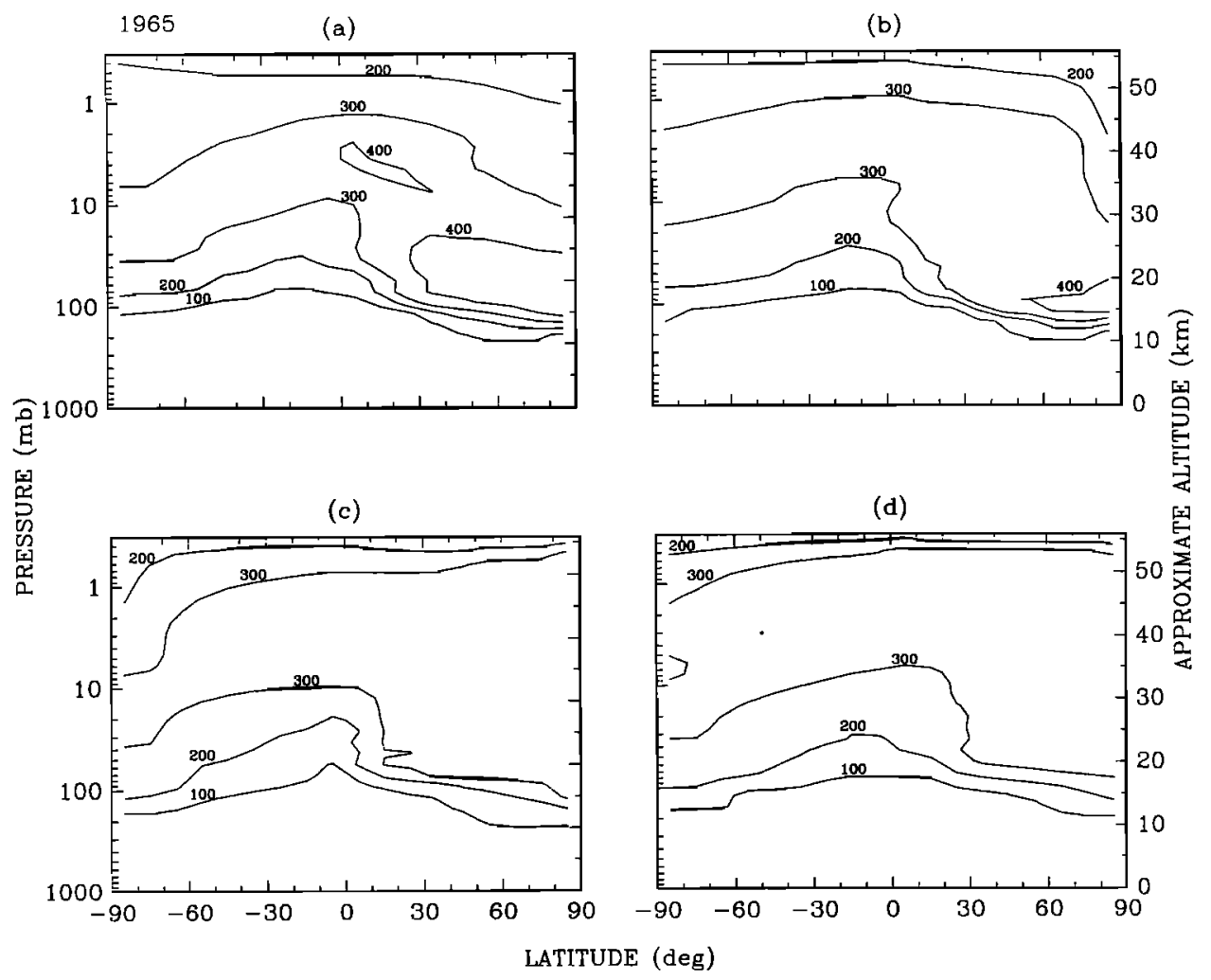

Fig. 7. Same as Figure 6 for 1965. 


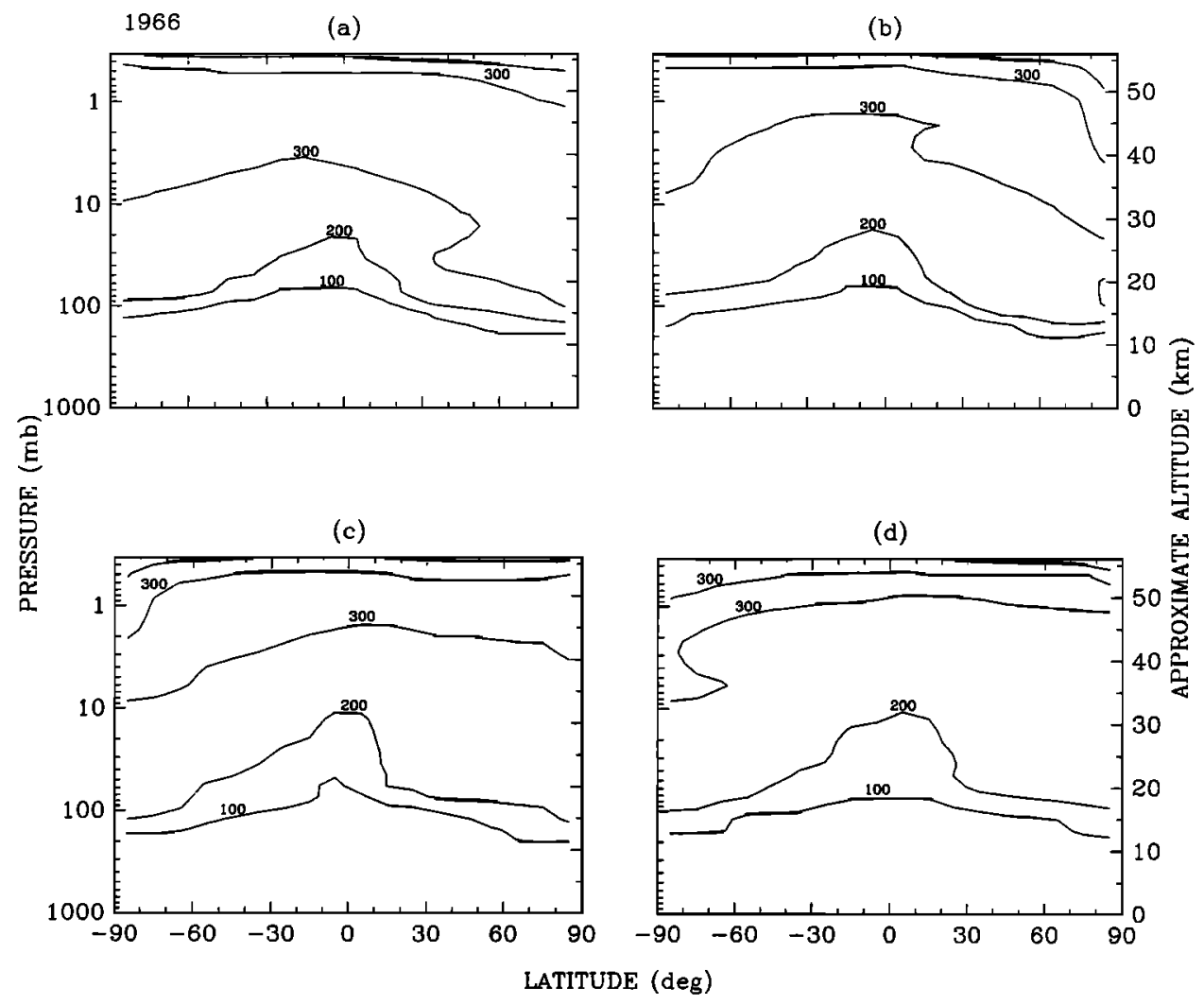

Fig. 8. Same as Figure 6 for 1966.

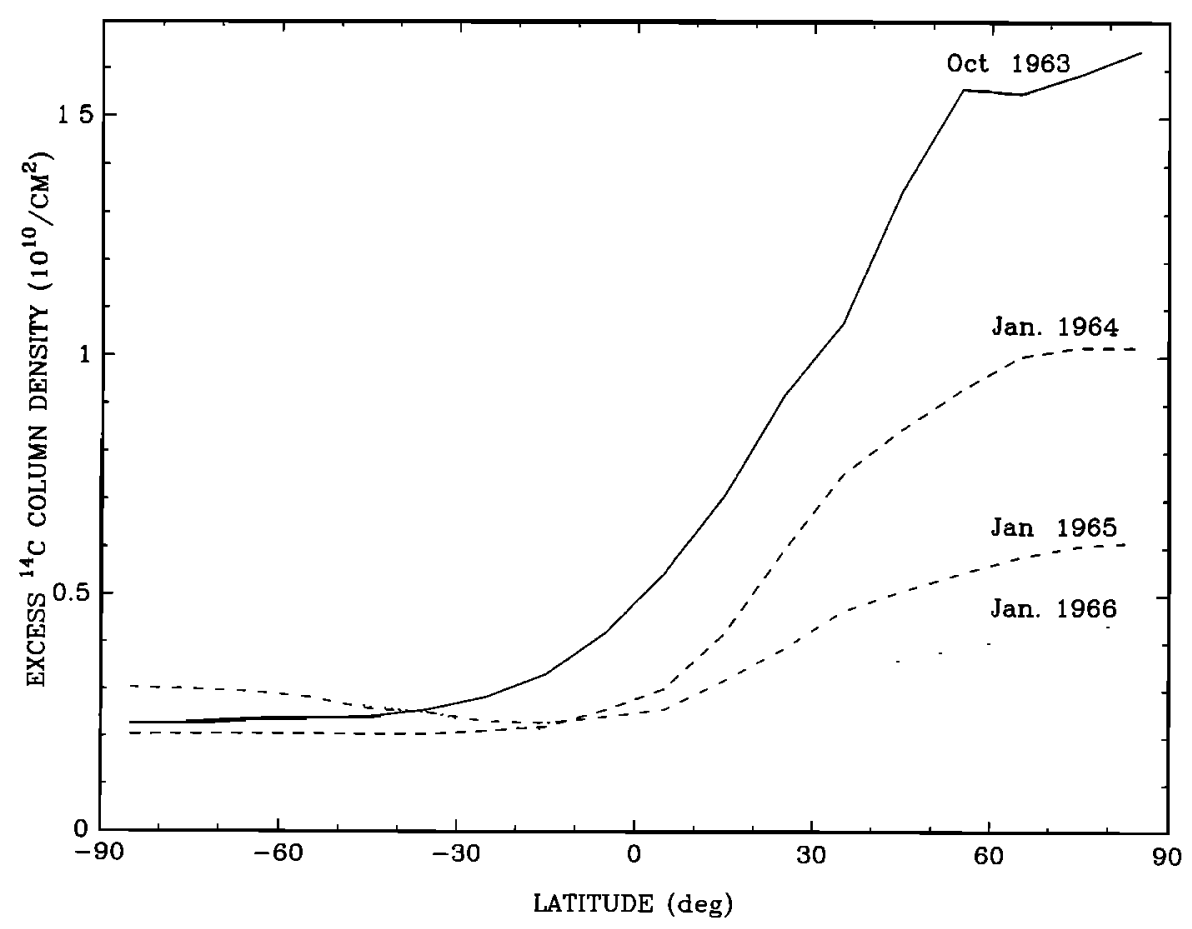

Fig. 9. Column density of excess ${ }^{14} \mathrm{C}$ above $10 \mathrm{~km}$ for October, 1963, and January, 1964-1966 in the standard model. 


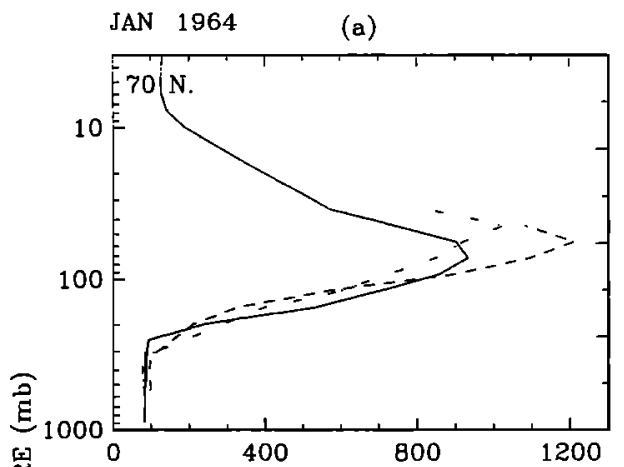

(b)
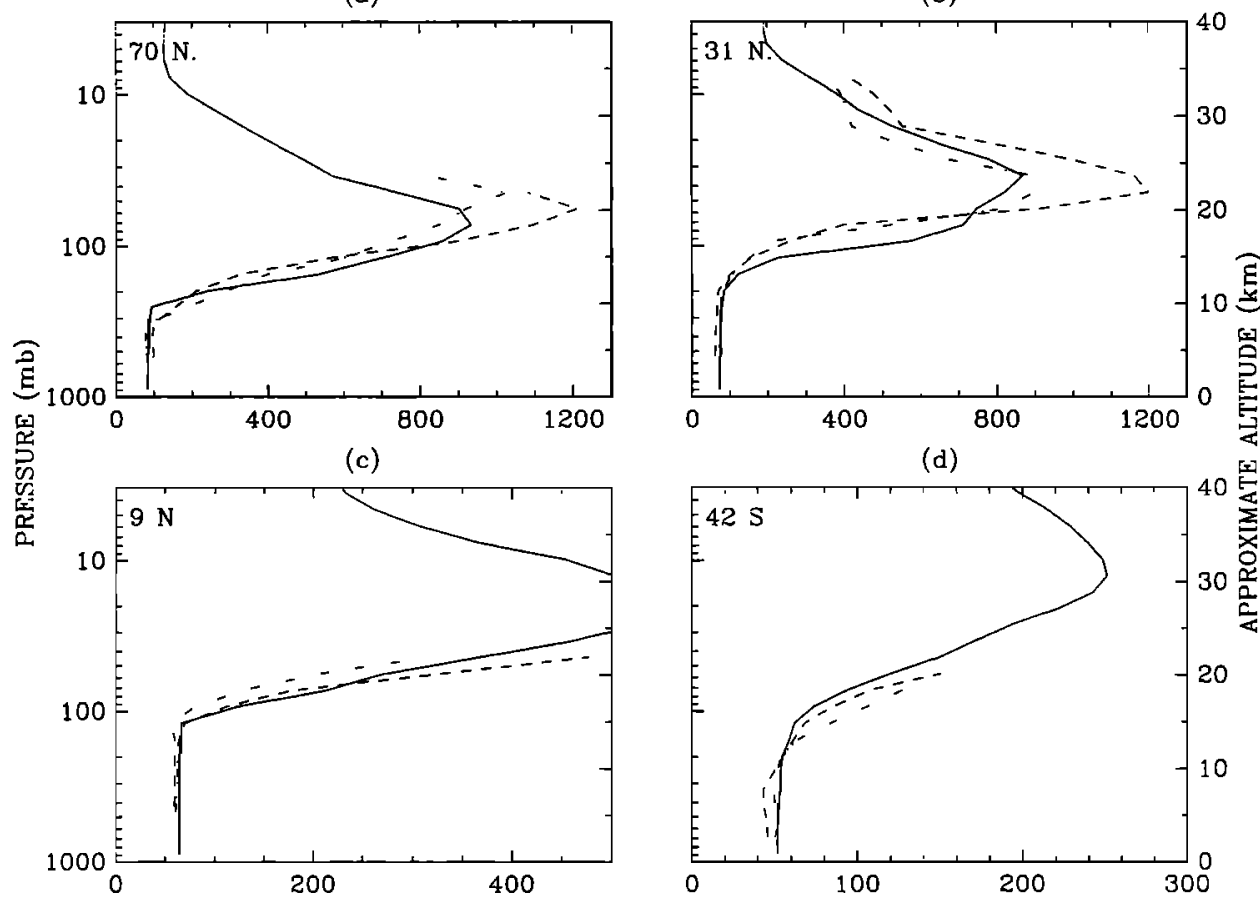

(d)

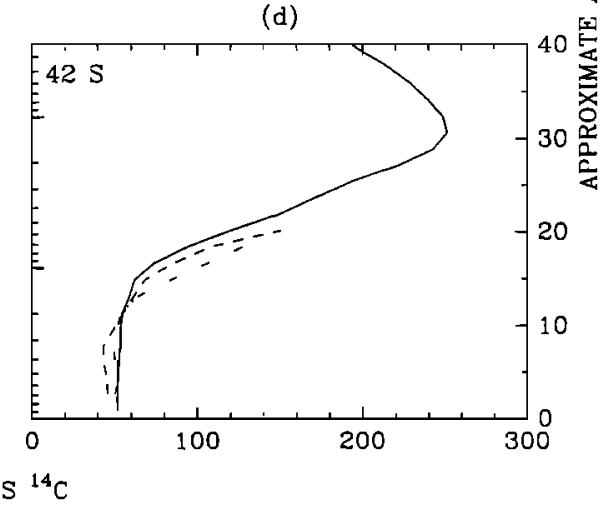

Fig. 10. Comparison of standard model and data for January, 1964 at $70^{\circ} \mathrm{N}, 31^{\circ} \mathrm{N}, 9^{\circ} \mathrm{N}$, and $42^{\circ} \mathrm{S}$. The units are same as in Figure 1. Model is represented by solid lines, initial data (October, 1963) by dashed lines, and January, 1964 data by dash-dot lines.

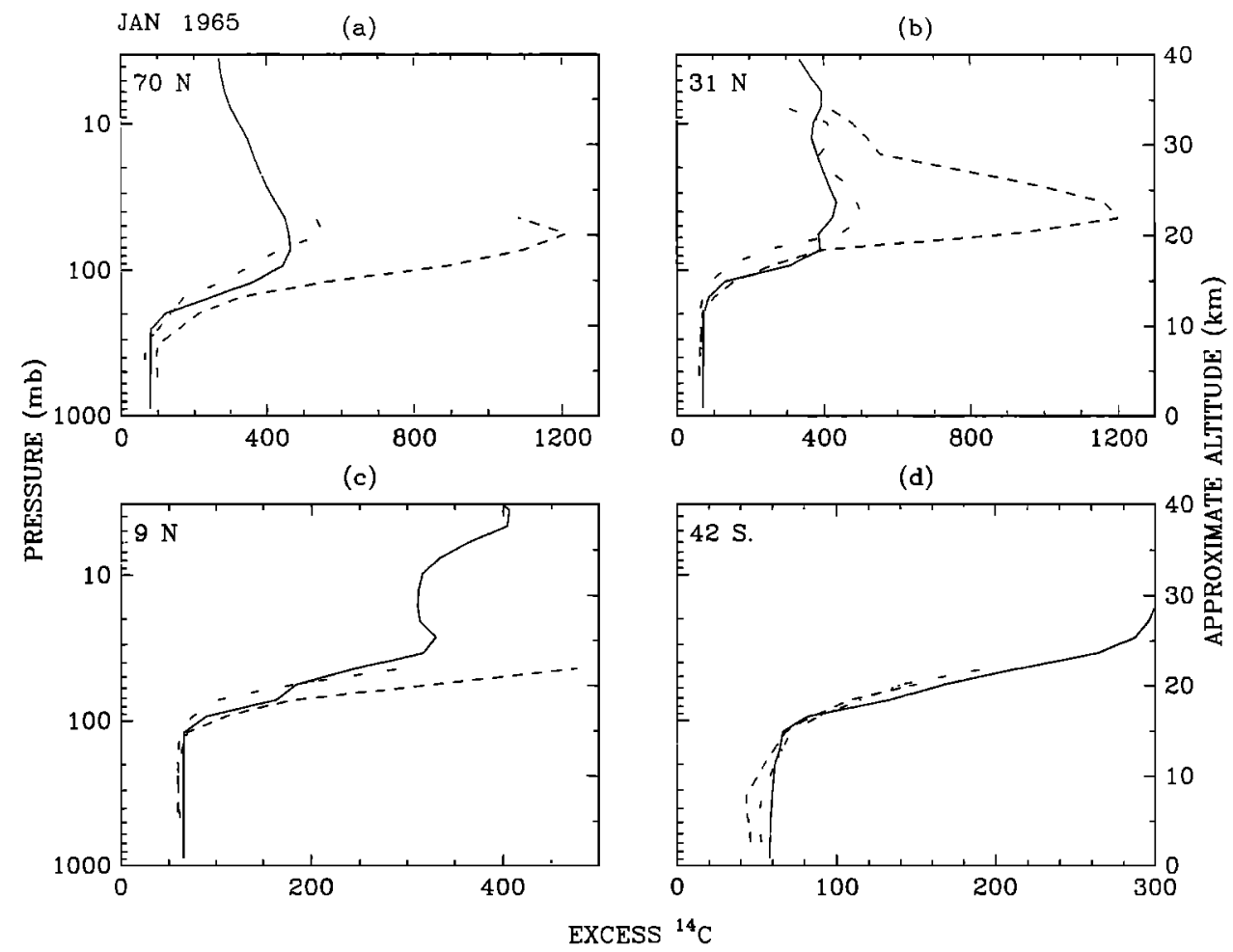

Fig. 11. Same as Figure 10 for January, 1965. 
sumes a horizontal structure resembling those of $\mathrm{NO}_{\mathrm{y}}$ and $\mathrm{O}_{3}$ with contour lines of constant mixing ratio lying parallel to the tropopause. The original hemispheric asymmetry has largely disappeared.

Quantitative comparison between modeling and data is shown for January, 1964 for selected latitudes $70^{\circ} \mathrm{N}, 31^{\circ} \mathrm{N}$, $9^{\circ} \mathrm{N}$, and $42^{\circ} \mathrm{S}$ in Figures $10 a-10 d$. The dashed lines represent the initial distribution (October, 1963). The dashdot lines represent the observed data (Johnston, 1988), and the solid lines are model computations. The comparison for later years, January, 1965-1966 is shown in Figures 11a-11d and $12 a-12 d$. In general, the agreement is good. This is significant because the transport coefficients used in the model have been previously validated by Tung and Yang [1988] and Yang and Tung [1989] for modeling stratospheric $\mathrm{O}_{3}$. We have not attempted any "tuning" except for adjusting the surface deposition velocity. Unfortunately, the lack of a complete data base for excess ${ }^{14} \mathrm{C}$ does not permit a critical test of our model transport in the upper stratosphere $(z>30 \mathrm{~km})$ or at high latitudes in the southern hemisphere.

\section{SENSITIVITY TESTS}

A large number of model runs have been performed to test the sensitivity of our results to the transport coeffcients. We start with the standard model as described in the previous section, and repeat the runs by varying one set of transport coefficients at a time. The different test cases are summarized in Table 2, along with brief comments on how the results compare with the observations.

In model A1, we increase the stream function uniformly in the atmosphere by a factor of 2 to produce a faster circulation. This run clearly shows that the advection is too fast, as can be seen from the comparison between model and observation in 1964 presented in Figures 13a-13d. The loss of material from the northern hemisphere is too great (see Figures $13 a$ and $13 b$ ). The results of the later years (not shown) reinforce this conclusion. For instance, in 1966 the model has generally half the observed excess ${ }^{14} \mathrm{C}$. The stream function is halved in model A2 to create a weaker circulation. The results for 1964 are shown in Figures 14a-14d. Note that in this case the results are not in serious conflict with observations, except perhaps near the tropopause at $31^{\circ} \mathrm{N}$, where the model profile does not have enough upwelling. The results of the later years (not shown) give values that are about $30 \%$ too high when compared with observations, suggesting that the reduced circulation cannot satisfactorily account for the loss of excess ${ }^{14} \mathrm{C}$ from the stratosphere.

What is the implication of these runs for other twodimensional models? We shall make a crude assessment. In our standard model the maximum upwelling velocity at $100 \mathrm{mbar}$ is $w_{\max }=2.9 \times 10^{-2} \mathrm{~cm} \mathrm{~s}^{-1}$. By comparison, this velocity is $0.1 \mathrm{~cm} \mathrm{~s}^{-1}$ in the work by Murgatroyd and Singleton [1961]. But most models [Guthrie et al., 1984; Ko et al., 1985; Stordal et al., 1985] use the heating rates of Murgatroyd and Singleton, scaled down by a factor of 0.4 . Thus, the corresponding $w_{\max }$ is about $4 \times 10^{-2} \mathrm{~cm} \mathrm{~s}^{-1}$. Garcia and Solomon [1983] prescribe vertical velocities at $100 \mathrm{mbar}$ in their model, with $w_{\max }=7 \times 10^{-2} \mathrm{~cm} \mathrm{~s}^{-1}$. Thus, in model $\mathrm{A} 1$ we have $w_{\max }=5.8 \times 10^{-2} \mathrm{~cm} \mathrm{~s}^{-1}$, a value intermediate between most groups and Garcia and Solomon. Our work suggests that the advection used by Garcia and Solomon may be too large. However, the exchange of mass between the troposphere and the stratosphere depends on the width of the Brewer-Dobson circulation and seasonal variations as well. Therefore, no definitive statements can

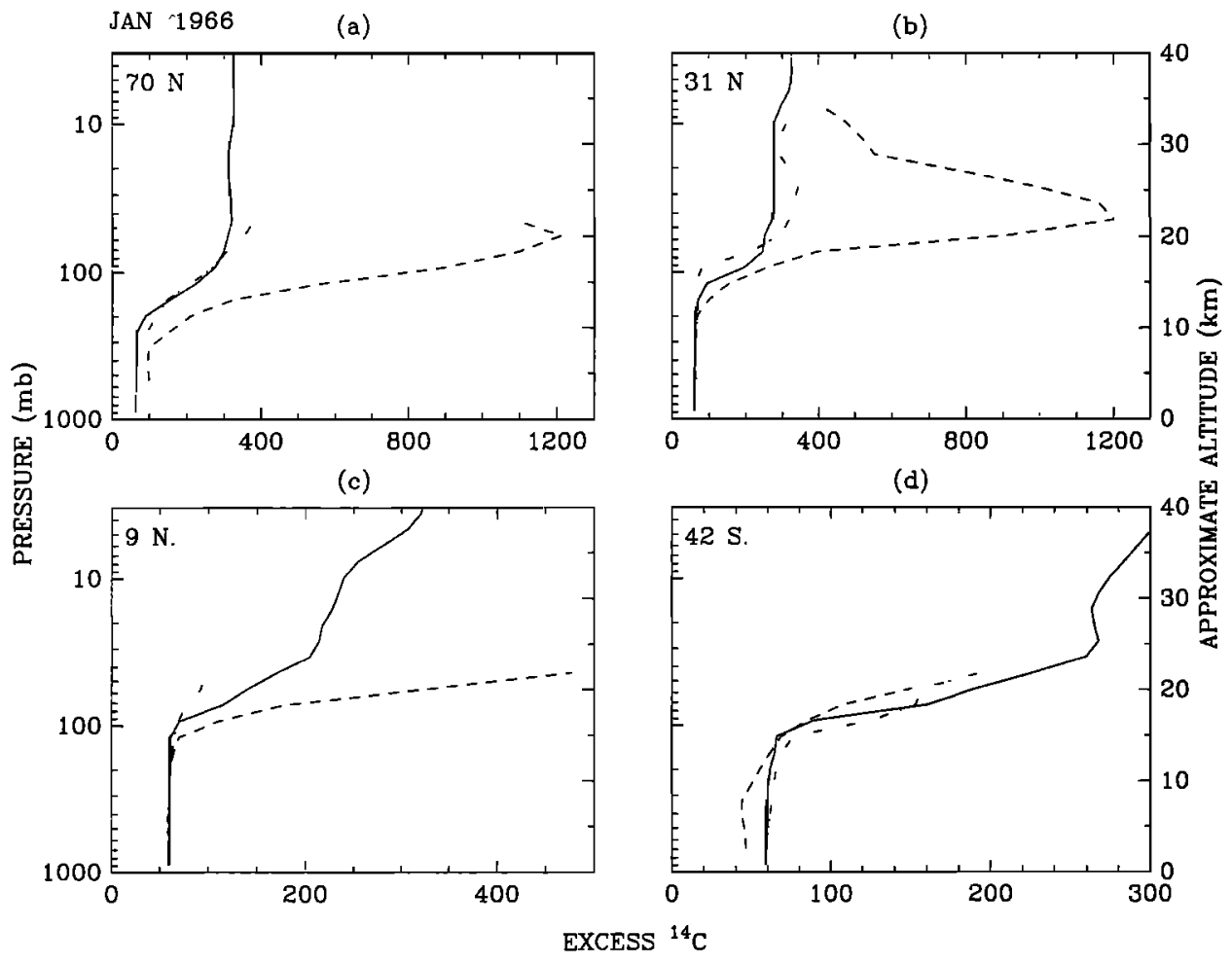

Fig. 12. Same as Figure 10 for January, 1966. 
TABLE 2. Summary of Runs Performed to Test the Sensitivity of our Model to Variations in the Transport Coefficients

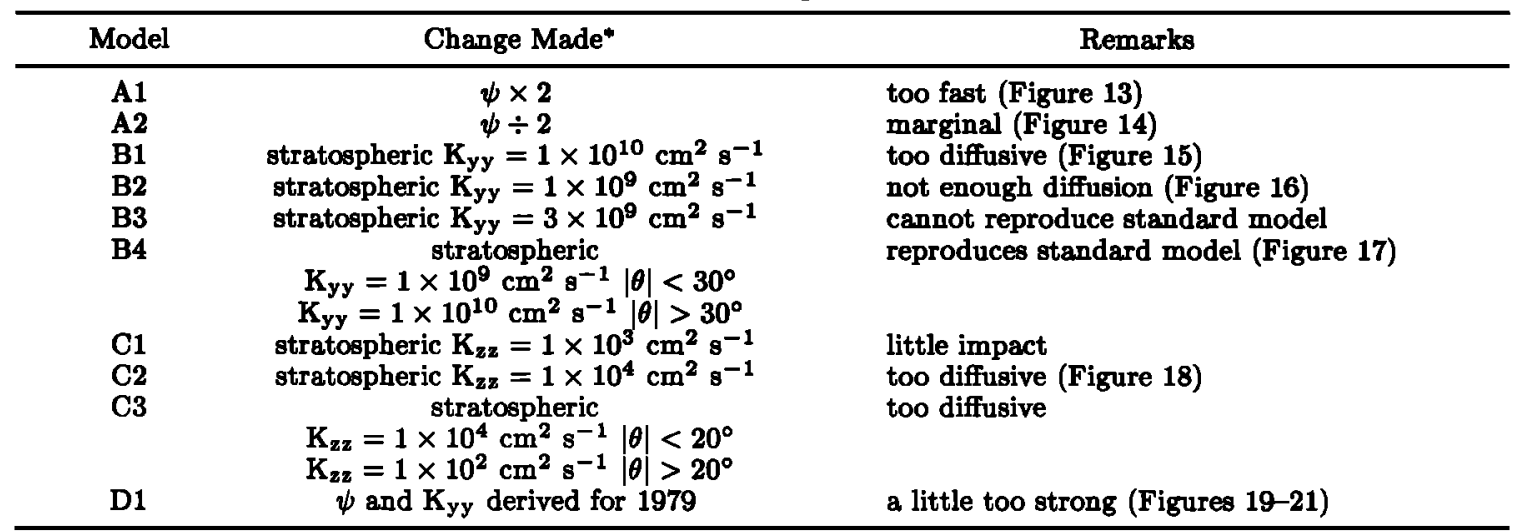

*Everything remains the same as in the standard model unless otherwise stated.

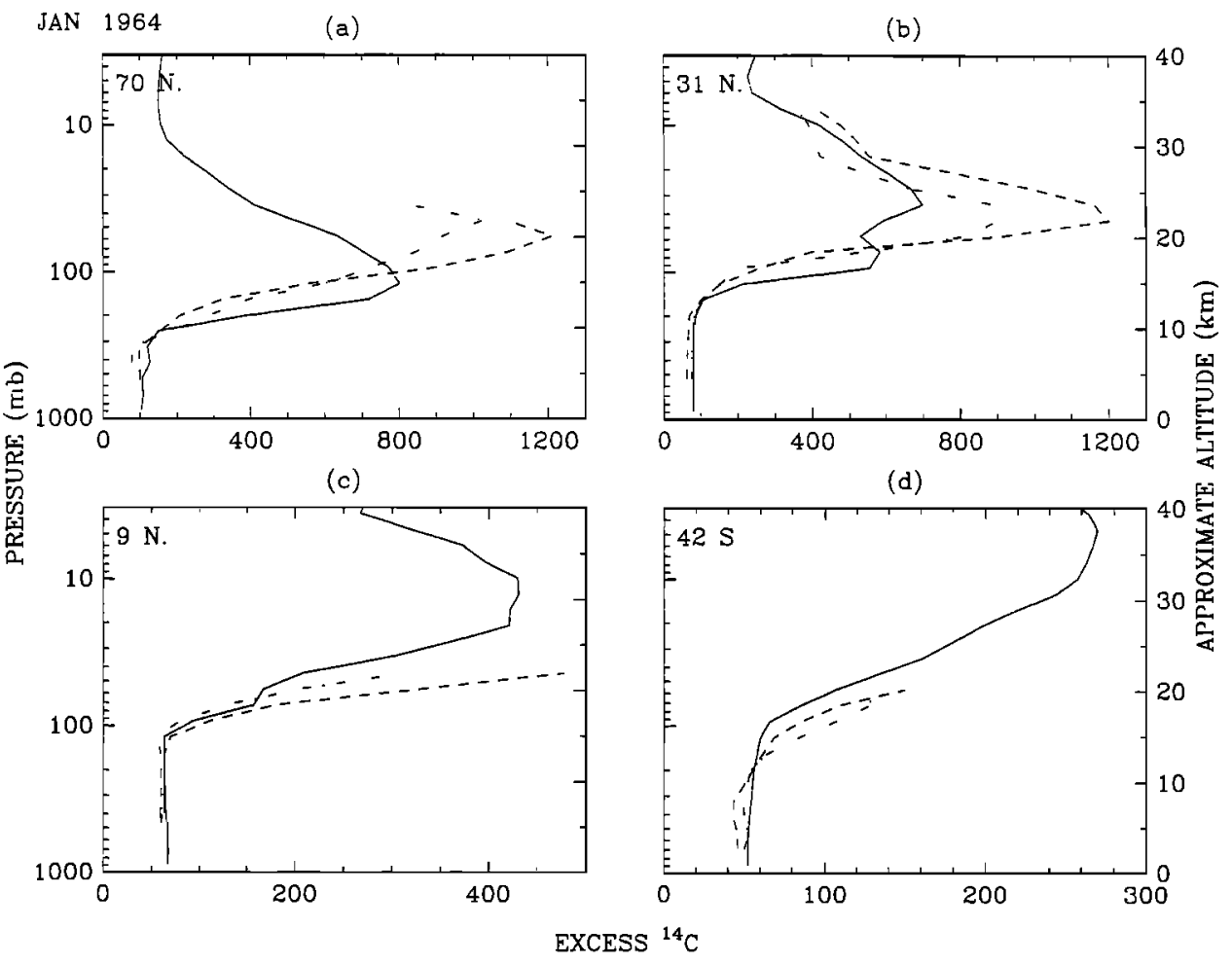

Fig. 13. Same as Figure 10 for model A1 using $\psi \times 2$.

be made until these model groups have carried out their own simulations of the excess ${ }^{14} \mathrm{C}$ data. The implication of model A2 is well known. A circulation that is half as strong as our standard model is obviously too sluggish because it would not be able to simulate the equatorial ozone minimum (see the detailed discussion of this constraint by Tung and Yang [1988]).

In model $\mathrm{B} 1$, the values of $\mathrm{K}_{\mathbf{y y}}$ in the stratosphere are set equal to $1 \times 10^{10} \mathrm{~cm}^{2} \mathrm{~s}^{-1}$. The results for January, 1964 are shown in Figures $15 a-15 d$. The rate of loss of material from the peak region is clearly too fast (see Figure $15 b$ for $31^{\circ} \mathrm{N}$ ). The results for the later years (not shown) show generally poor agreement with the observations. Model B2 is similar to model B1 except that $K_{y y}=1 \times 10^{9} \mathrm{~cm}^{2} \mathrm{~s}^{-1}$ in the stratosphere. The results for January, 1964 are given in Figures $16 a-16 d$. In this case, it is clear that the downward air motion (advection) dominates the lateral diffusion. As illustrated in Figure $16 a$, the excess ${ }^{14} \mathrm{C}$ peak, while having the correct magnitude, is displaced downward by as much as $3 \mathrm{~km}$. The results of these models are consistent with those of $K o$ et al. [1985], who conclude that a smaller $K_{\mathbf{y y}}$ allows more $\mathrm{HNO}_{3}$ to descend deeper into the lower polar 


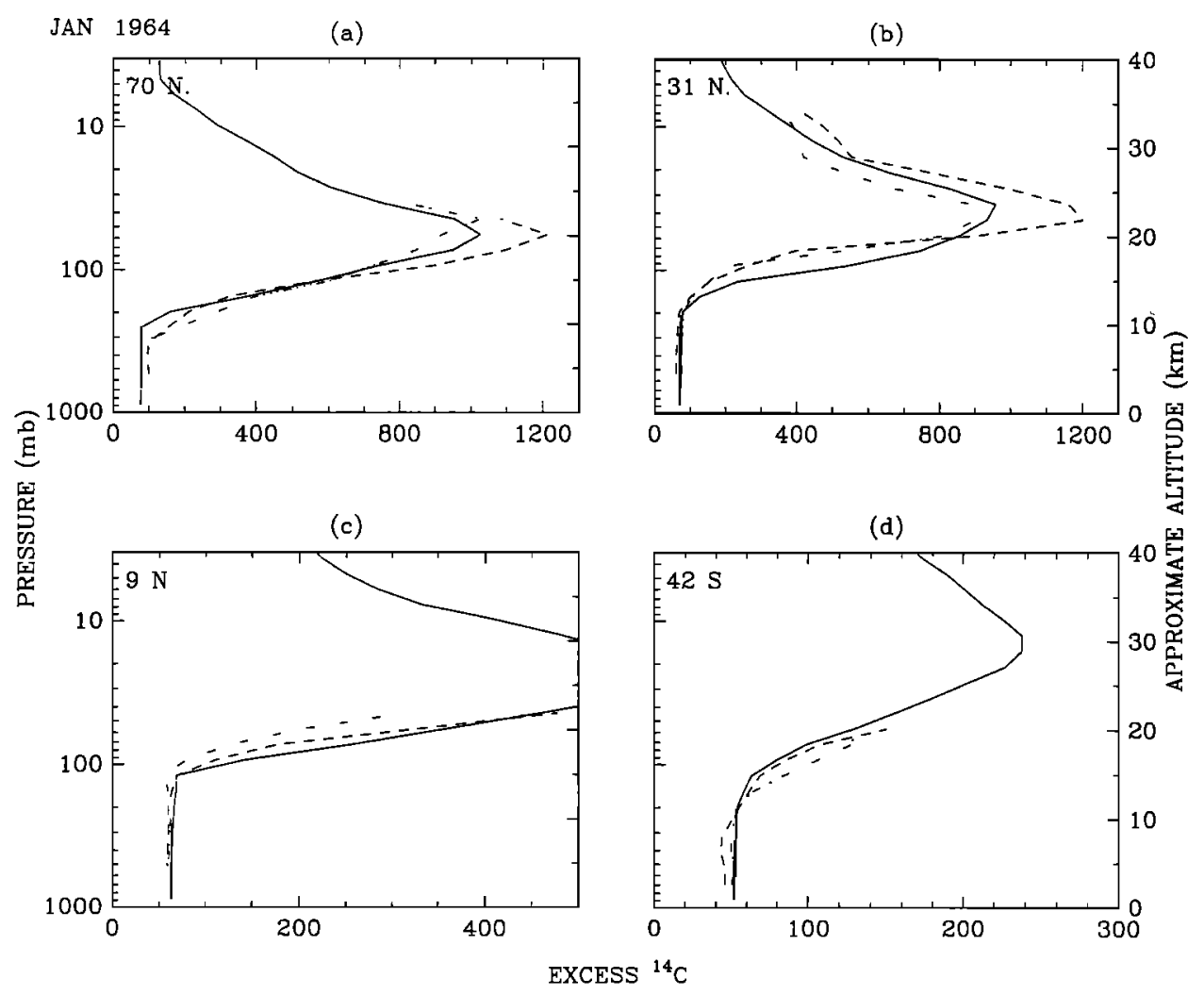

Fig. 14. Same as Figure 10 for model A2 using $\psi \div 2$.

JAN. 1964

(a)

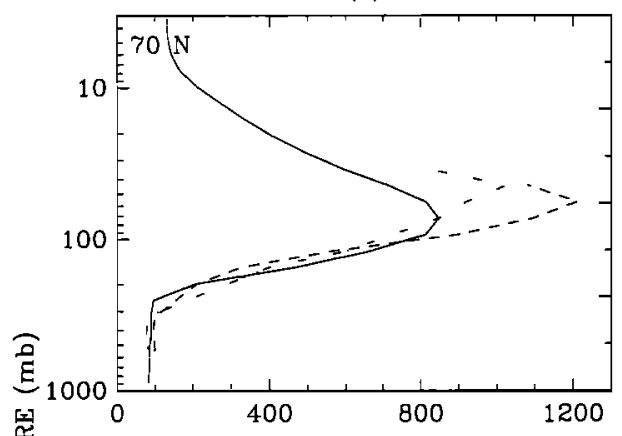

(c)

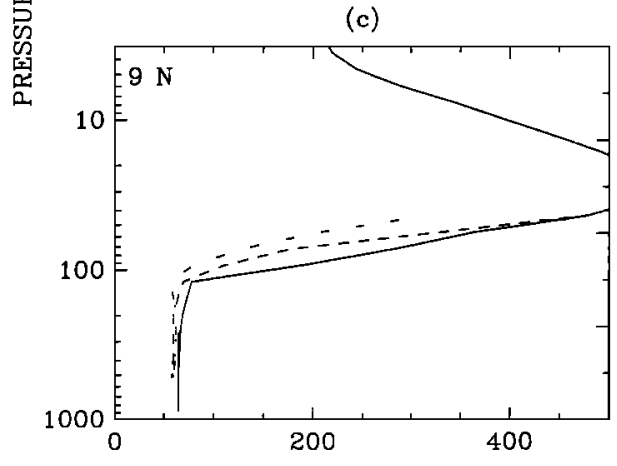

(b)

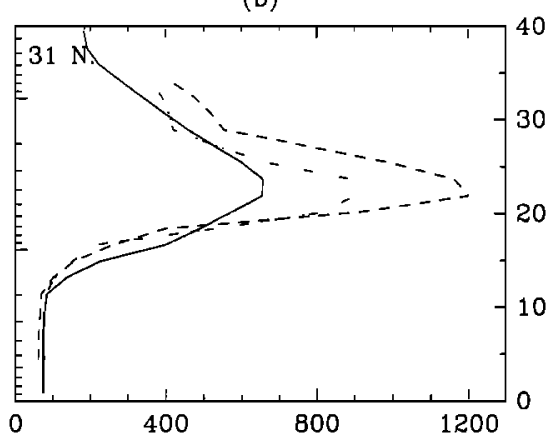

(d)

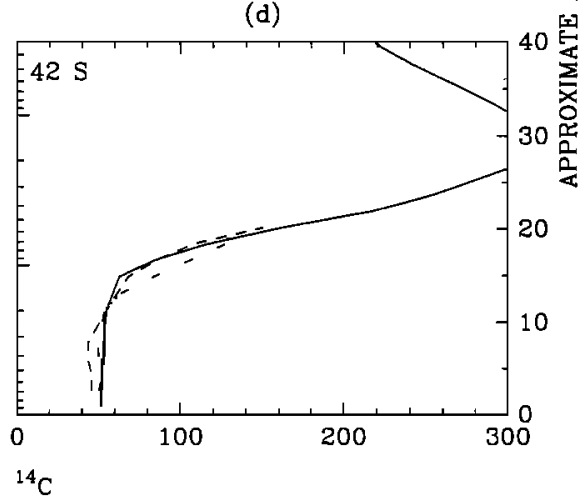

Fig. 15. Same as Figure 10 for model B1 with stratospheric $K_{y y}=1 \times 10^{10} \mathrm{~cm}^{2} \mathrm{~s}^{-1}$. 
JAN. 1964

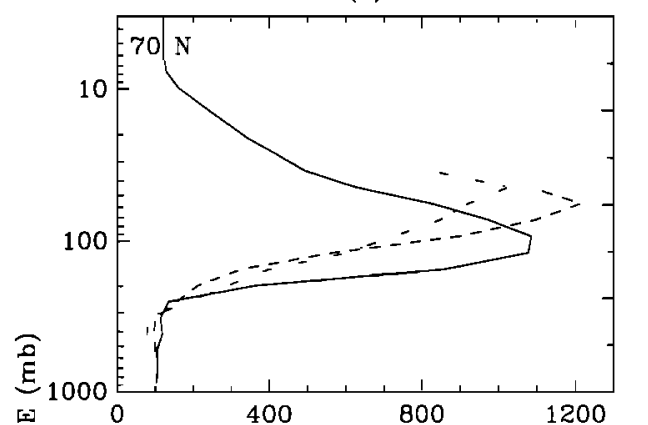

(c)

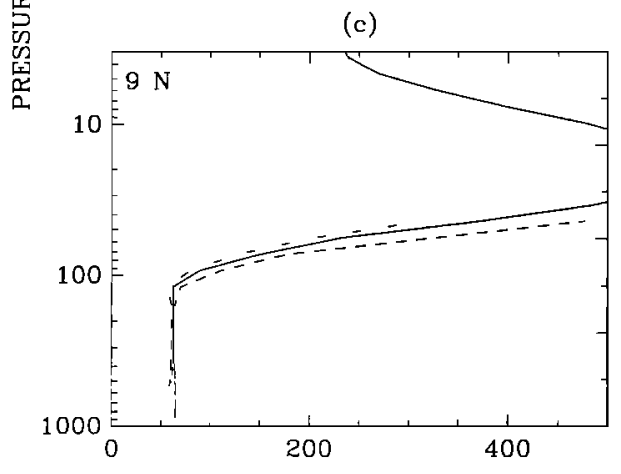

(b)

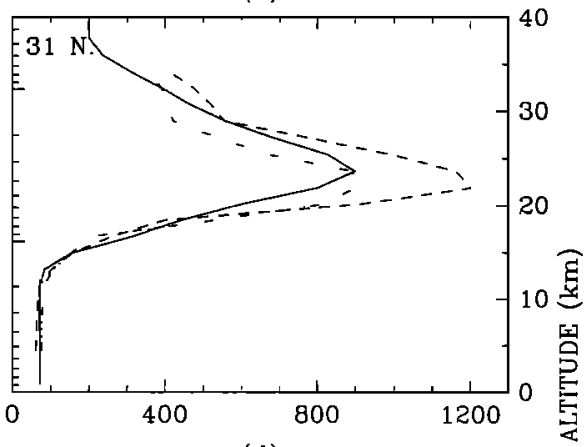

(d)

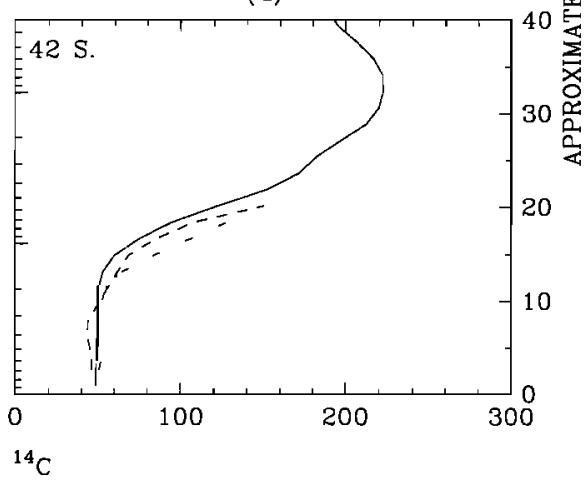

Fig. 16. Same as Figure 10 for model $B 2$ with stratospheric $K_{y y}=1 \times 10^{9} \mathrm{~cm}^{2} \mathrm{~s}^{-1}$.

stratosphere, thus creating a greater latitudinal contrast in the column abundances. No single constant value of stratospheric $K_{y y}$ in the range $1-10 \times 10^{9} \mathrm{~cm}^{2} \mathrm{~s}^{-1}$ can reproduce the overall good agreement between our standard model and the observations. The reason is obvious from models B1 and B2. The low latitude data require a low $K_{y y}$ and the high latitude data require a high $\mathrm{K}_{\mathrm{yy}}$. A model such as model B3, with $\mathrm{K}_{\mathrm{yy}}=3 \times 10^{9} \mathrm{~cm}^{2} \mathrm{~s}^{-1}$, cannot satisfy both demands. This provides support for the nonconstant $K_{y y}$ derived by the self-consistent theory [Tung, 1984, 1986; Plumb and Mahlman, 1987; Newman et al., 1988; Yang and Tung, 1989], a result independently tested here using a very sensitive tracer.

Figures 5a-5d suggest that $\mathrm{K}_{\mathrm{yy}}$ is larger in the tropics. A bimodal value of stratospheric $K_{y y}$ equal to $1 \times 10^{9} \mathrm{~cm}^{2} \mathrm{~s}^{-1}$ for latitudes below $30^{\circ}$ and $1 \times 10^{10} \mathrm{~cm}^{2} \mathrm{~s}^{-1}$ for higher latitudes (model B4) can closely reproduce our standard model for all years. The results for January, 1964 are shown in Figures $17 a-17 d$. In the model of $K o$ et al. [1985] a constant stratospheric $K_{y y}$ is used. A bimodal $K_{y y}$ like that of model B4 can probably improve the agreement of their latitudinal distribution of $\mathrm{HNO}_{3}$. However, we must caution the reader not to regard this as a substitute for the selfconsistent $K_{y y}$, because of the sparse data base on which this bimodal $K_{y y}$ rests. Any other $K_{y y}$ with a small value in the equatorial lower stratosphere, and a higher value at high latitudes, where the Brewer-Dobson circulation is descending, will probably reproduce model B4.

Although there are no theoretical reasons for a large $K_{\mathbf{z z}}$ in the stratosphere, it is of interest to set an upper limit for $K_{\mathbf{z z}}$. In model $\mathrm{C1}$ we set the stratospheric $\mathrm{K}_{\mathbf{z z}}=1 \times 10^{3}$ $\mathrm{cm}^{2} \mathrm{~s}^{-1}$, which is 10 times the value in the standard model. The results are virtually the same as in the standard model, and hence are not shown. A higher value $\mathrm{K}_{\mathrm{zz}}=1 \times 10^{4} \mathrm{~cm}^{2}$ $\mathrm{s}^{-1}$ is used in model C2. The results for January, 1964 are presented in Figure 18. The $70^{\circ} \mathrm{N}$ and $31^{\circ} \mathrm{N}$ (Figures $18 a$ and $18 b$ ) comparisons clearly show that this model is too diffusive. The loss of excess ${ }^{14} \mathrm{C}$ in later years (not shown) is also very severe, and by 1966 the computed excess ${ }^{14} \mathrm{C}$ is only about half the observed value. Thus we conclude that $\mathrm{K}_{\mathrm{zz}}$ must be less than $5 \times 10^{3} \mathrm{~cm}^{2} \mathrm{~s}^{-1}$ in the stratosphere. Most "modern" two-dimensional models have $\mathrm{K}_{\mathrm{zz}}$ less than $3 \times 10^{3} \mathrm{~cm}^{2} \mathrm{~s}^{-1}$, with the exception of two models. Garcia and Solomon [1983] use a $K_{\mathrm{zz}}$ that increases steeply with altitude. Below $26 \mathrm{~km} \mathrm{~K} \mathrm{Kz}_{2}<1 \times 10^{4} \mathrm{~cm}^{2} \mathrm{~s}^{-1}$, but rises to $>1 \times 10^{5} \mathrm{~cm}^{2} \mathrm{~s}^{-1}$ above $40 \mathrm{~km}$. This choice of $\mathrm{K}_{\mathrm{zz}}$ may be too high to be consistent with our data. Pitari and Visconti [1985] derive their residual mean circulation and eddy diffusion coefficients from the MIT-GIT GCM. They report values of $K_{\mathrm{zz}}>1 \times 10^{4} \mathrm{~cm}^{2} \mathrm{~s}^{-1}$ in the equatorial lower stratosphere. In model $\mathrm{C} 3$ we attempt to represent their $\mathrm{K}_{\mathrm{zz}}$ by a bimodal value, $\mathrm{K}_{\mathrm{zz}}=1 \times 10^{4} \mathrm{~cm}^{2} \mathrm{~s}^{-1}$ for $|\theta|<20^{\circ}$ and $\mathrm{K}_{\mathrm{zz}}=1 \times 10^{2} \mathrm{~cm}^{2} \mathrm{~s}^{-1}$ for $|\theta|>20^{\circ}$. The results suggest that $K_{\mathrm{zz}}$ as large as $1 \times 10^{4} \mathrm{~cm}^{2} \mathrm{~s}^{-1}$ concentrated only in the tropics is too diffusive.

As mentioned earlier, the choice of using the circulation and $K_{y y}$ of 1980 to simulate the transport of excess ${ }^{14} \mathrm{C}$ in the years 1963-1966 is arbitrary and is dictated mostly by the availability of stratospheric temperature data in the NMC series. In fact, 1980 corresponds to a year of relatively weak stratospheric wave activity. In model D1 we repeat the calculations with the circulation and $K_{y y}$ of 1979 


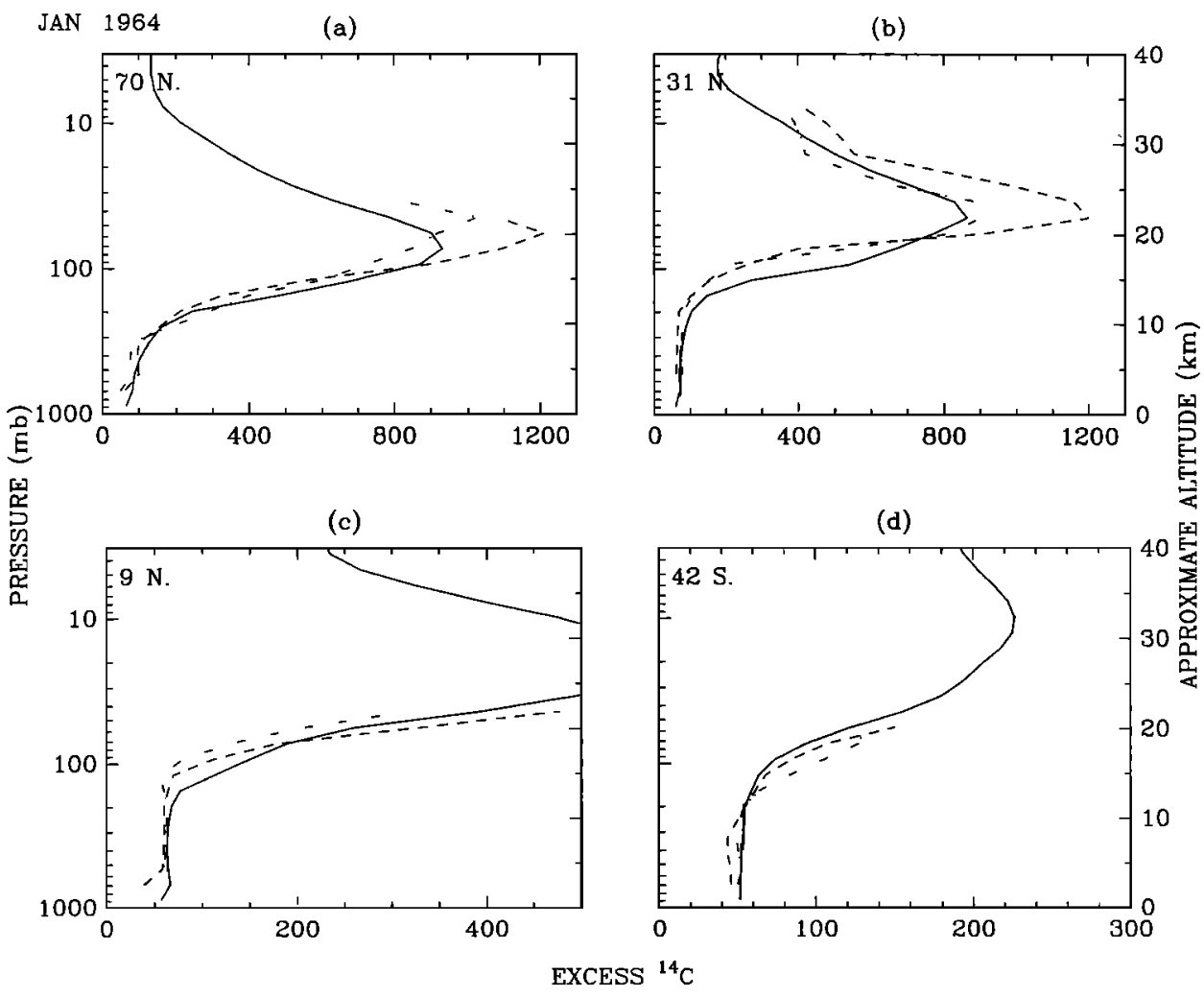

Fig. 17. Same as Figure 10 for model B4, with stratospheric $K_{y y}=1 \times 10^{9} \mathrm{~cm}^{2} \mathrm{~s}^{-1}$ for $|\theta|<30^{\circ}$, and $\mathrm{K}_{\mathrm{yy}}=1 \times 10^{10} \mathrm{~cm}^{2} \mathrm{~s}^{-1}$ for $|\theta|>30^{\circ}$.

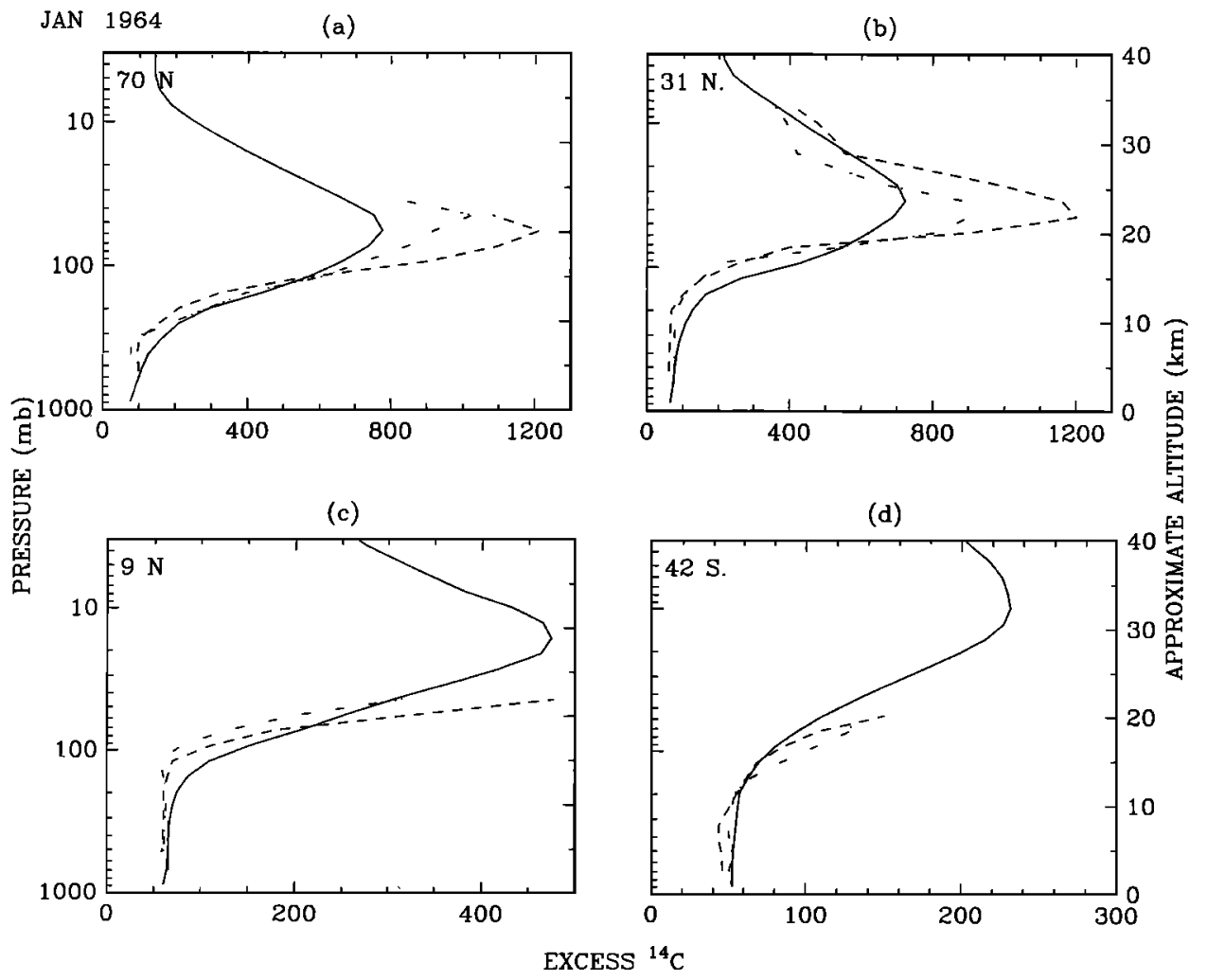

Fig. 18. Same as Figure 10 for model C2, with stratospheric $K_{\mathrm{zz}}=1 \times 10^{4} \mathrm{~cm}^{2} \mathrm{~s}^{-1}$. 
[Tung and Yang, 1988], a year of very strong stratospheric wave activity. The results, summarized in Figures $19 a-19 d$, $20 a-20 d$, and 21a-21d for January, 1964, 1965, and 1966, respectively, suggest that although there are differences in the simulations using 1979 and 1980 transport coefficients, these cannot be distinguished using the current data base. We have also carried out simulations using transport coefficients derived from the GFDL three-dimensional model (Zurek et al., 1989). The results are not as good as those based on Yang and Tung [1989], again demonstrating the sensitivity of our model to different input parameters. However, a detailed comparison of this model with other models will be referred to Zurek et al. (1989).

\section{TROPOSPHERE}

The main thrust of this work is modeling of the stratosphere. However, correct modeling of tropospheric excess ${ }^{14} \mathrm{C}$ is crucial for a correct treatment of its stratospheric abundances. We believe that this is the first time that excess ${ }^{14} \mathrm{C}$ has been traced from its source in the stratosphere to its ultimate sink on the surface. The question arises as to what determines the abundance of excess ${ }^{14} \mathrm{C}$ near the surface. Clearly the essential elements in this question are the surface deposition velocity and the vertical transport and the interhemispheric exchange (parameterized here by a tropospheric $K_{z z}$ and $K_{y y}$, respectively).

Sensitivity runs are summarized in Table 3 . We choose to examine the results in January, 1966, by which time the model has reached a quasi-steady state between the stratosphere and the troposphere. In model $\mathrm{T} 1$, the surface de- position velocities $v_{S}$ and $v_{N}$ are set to zero. The computed excess ${ }^{14} \mathrm{C}$ at $5 \mathrm{~km}$ at $70^{\circ} \mathrm{N}, 31^{\circ} \mathrm{N}, 9^{\circ} \mathrm{N}$, and $42^{\circ} \mathrm{S}$ are $98,91,89$, and 84 units, respectively. Therefore, the prediction is too high compared with observations (see Table 3). In model $\mathrm{T} 2$, we raise the deposition velocities to $v_{S}=v_{N}=1 \times 10^{-2} \mathrm{~cm} \mathrm{~s}^{-1}$. In this case, the predicted values for excess ${ }^{14} \mathrm{C}$ are too low when compared with observations. In model T3, we set $v_{S}=v_{N}=3 \times 10^{-3} \mathrm{~cm}$ $\mathrm{s}^{-1}$. This case is fairly close to the observations, but there is apparently too much excess ${ }^{14} \mathrm{C}$ in the northern hemisphere. In model T4, we test the sensitivity of our results to a smaller equatorial $\mathrm{K}_{\mathrm{yy}}=3 \times 10^{9} \mathrm{~cm}^{2} \mathrm{~s}^{-1}$ in the troposphere. This run is not as good as the standard run and suggests that an interhemispheric barrier in the transport will enhance the excess ${ }^{14} \mathrm{C}$ gradient [see Pinto et al., 1983]. Model T5 tests the sensitivity of our results to a weaker vertical eddy diffusivity $\mathrm{K}_{\mathrm{zz}}=3 \times 10^{4} \mathrm{~cm}^{2} \mathrm{~s}^{-1}$ in the southern hemisphere. Again, this results in a greater hemispheric asymmetry in excess ${ }^{14} \mathrm{C}$. The need for asymmetric $v_{S}$ and $v_{N}$ can obviously be removed by a large $\mathrm{K}_{\mathrm{yy}}$. In model $\mathrm{T} 6$, we set $K_{y y}=3 \times 10^{10} \mathrm{~cm}^{2} \mathrm{~s}^{-1}$ and $v_{S}=v_{N}=4 \times 10^{-3}$ $\mathrm{cm} \mathrm{s}^{-1}$. The results for January, 1966 (see Table 3) are marginally acceptable. However, there are two flaws with this model. First, the time constant for diffusion over global scale as computed by (13) is now only 5.2 months. This is much shorter than the known interhemispheric exchange time. Second, the modeled tropospheric excess ${ }^{14} \mathrm{C}$ in 1964 and 1965 at $42^{\circ} \mathrm{S}$ are much larger than the observed values. The results summarized in Table 3 are not intended to be a definitive study of tropospheric excess ${ }^{14} \mathrm{C}$, but rather to provide some insight into how the transport parameters

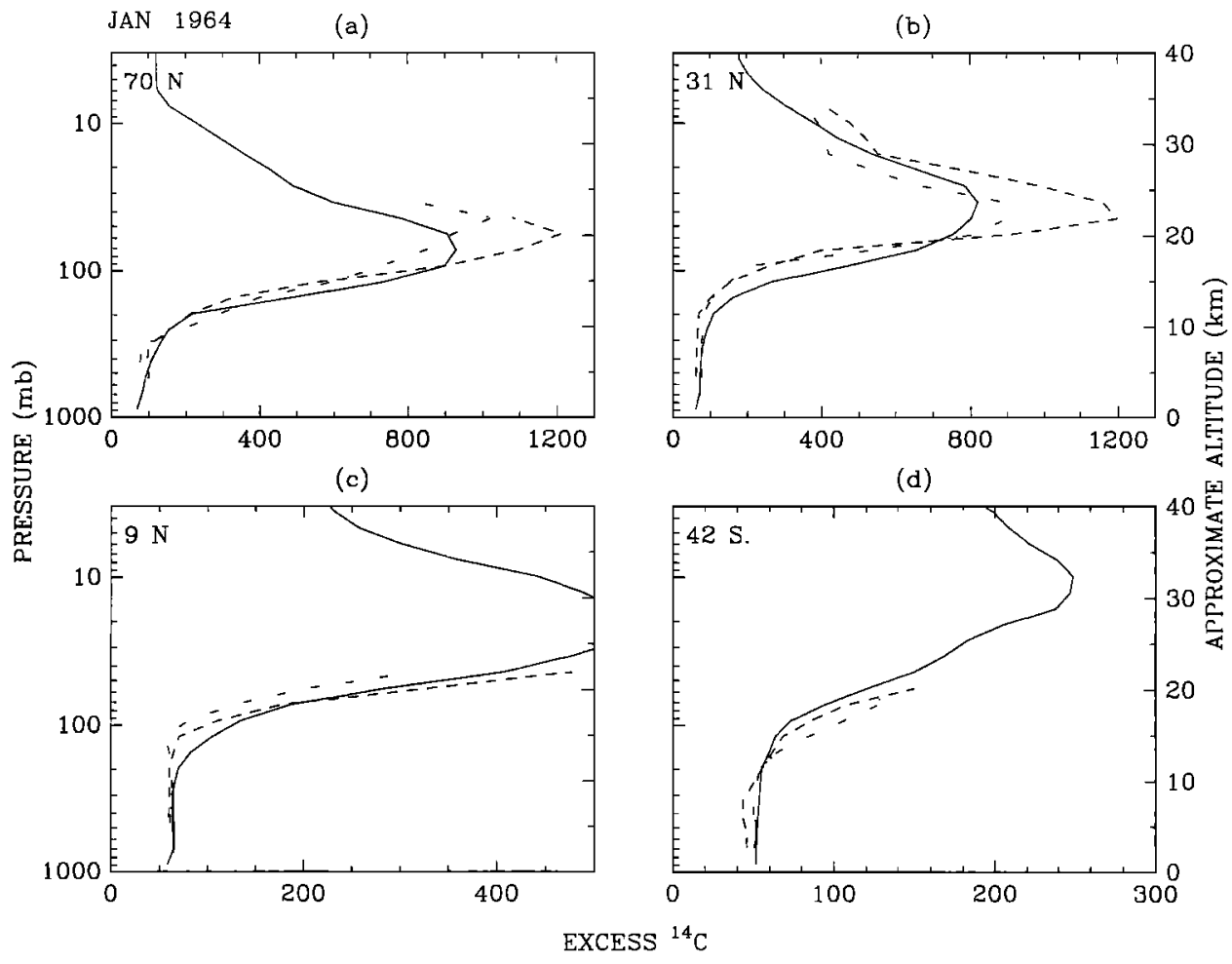

Fig. 19. Same as Figure 10, for model D1, and January, 1964 using $1979 \psi$ and $\mathrm{K}_{\mathrm{yy}}$. 


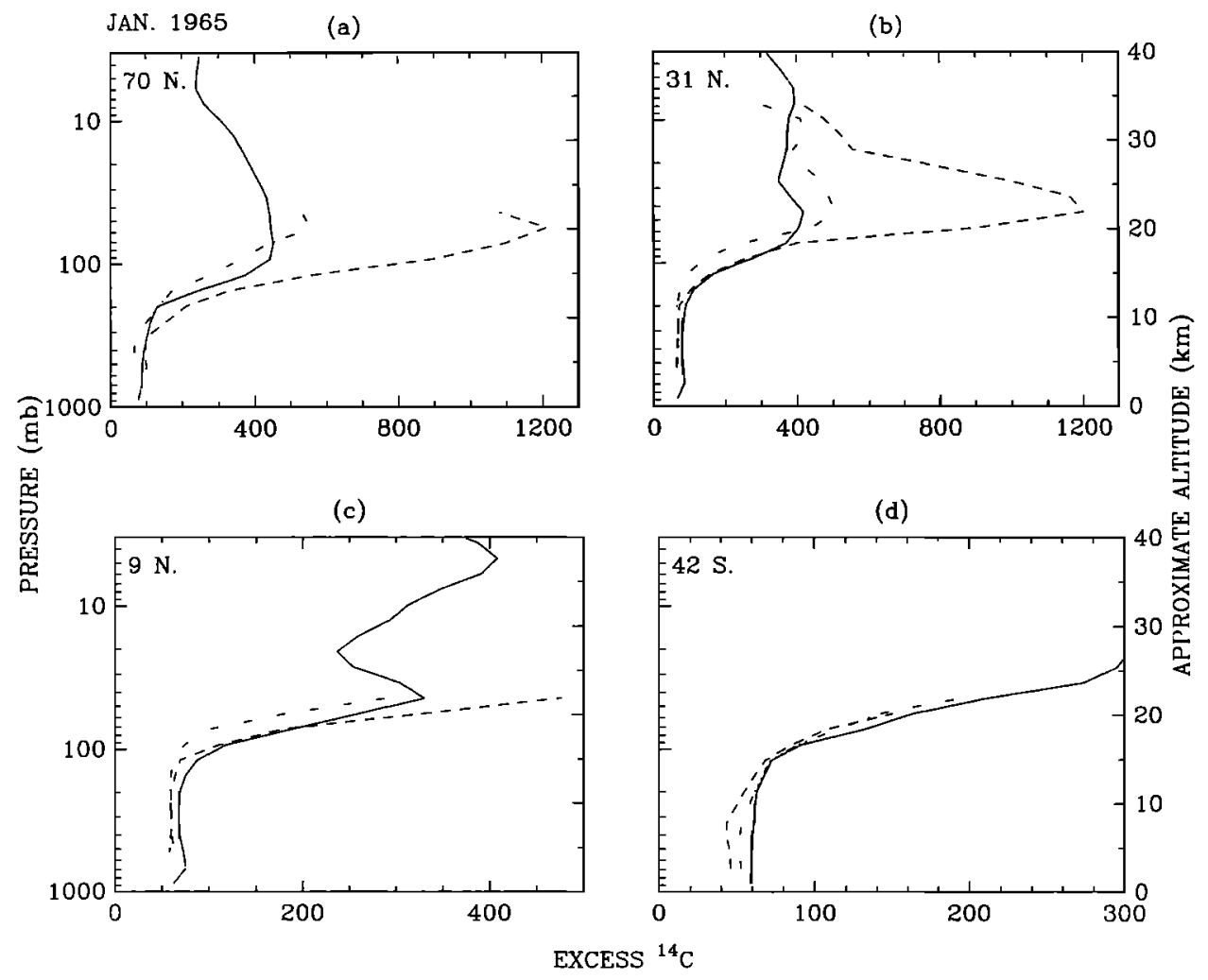

Fig. 20. Same as Figure 19, for January, 1965.

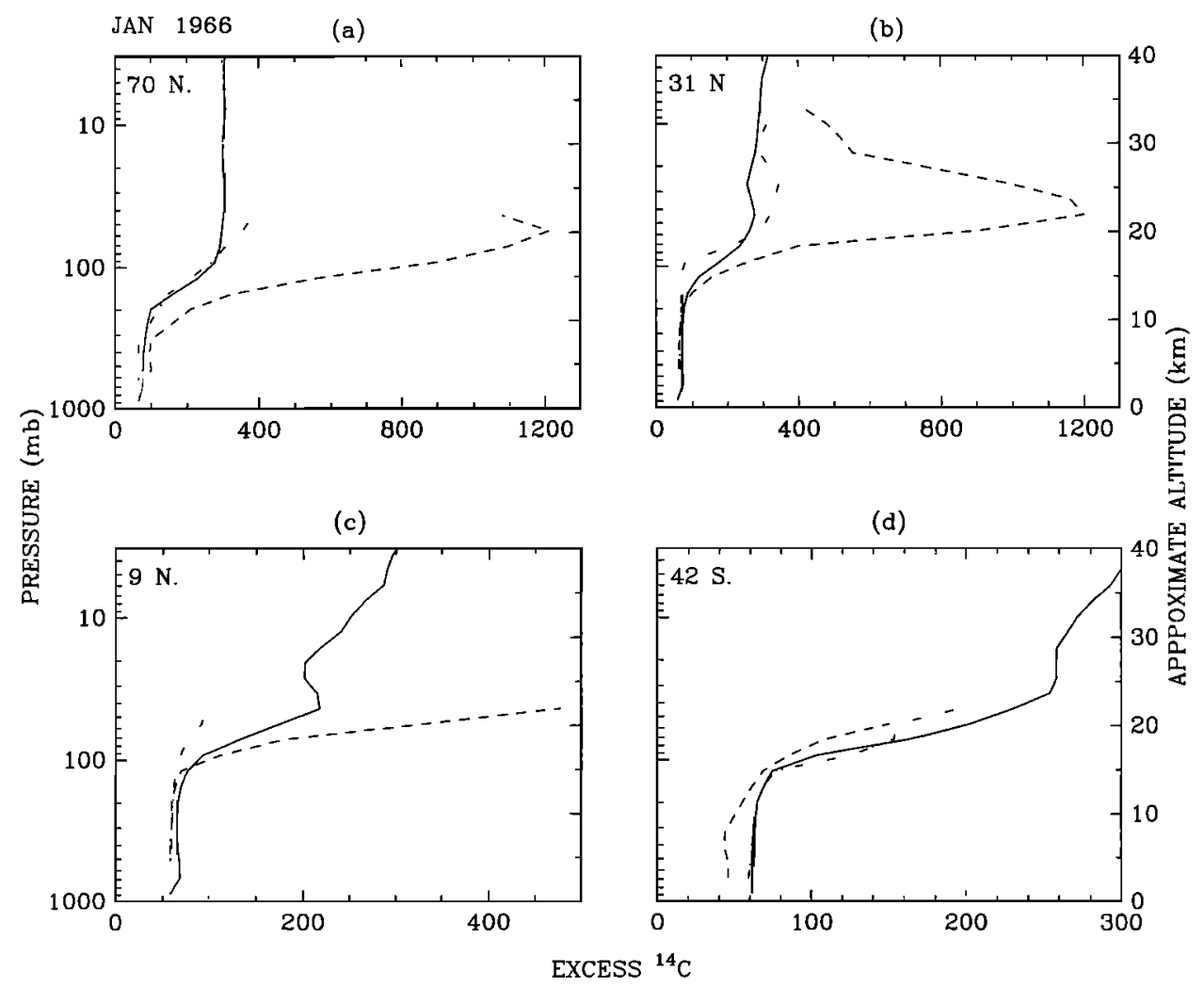

Fig. 21. Same as Figure 19, for January, 1966. 
TABLE 3. Summary of Model Runs Performed to Test the Sensitivity of Our Model to Surface Deposition Velocity and Tropospheric $\mathbf{K}_{\mathbf{y y}}$ and $\mathbf{K}_{\mathbf{z z}}$

\begin{tabular}{|c|c|c|c|c|c|c|}
\hline \multirow[b]{2}{*}{ Model } & \multirow[b]{2}{*}{ Change } & \multicolumn{4}{|c|}{ Excess ${ }^{14} \mathrm{C}$} & \multirow[b]{2}{*}{ Remarks } \\
\hline & & $70^{\circ} \mathrm{N}$ & $31^{\circ} \mathrm{N}$ & $9^{\circ} \mathbf{N}$ & $42^{\circ} \mathrm{S}$ & \\
\hline $\begin{array}{l}\text { T1 } \\
\text { T2 } \\
\text { T3 } \\
\text { T4 }\end{array}$ & $\begin{array}{c}v_{S}=v_{N}=0 \\
v_{S}=v_{N}=1 \times 10^{-2} \mathrm{~cm} \mathrm{~s}^{-1} \\
v_{S}=v_{N}=3 \times 10^{-3} \mathrm{~cm} \mathrm{~s}^{-1} \\
\text { Tropospheric } \mathbf{K}_{\mathrm{yy}}=3 \times 10^{9} \mathrm{~cm}^{2} \mathrm{~s}^{-1} \\
|\theta|<20^{\circ}\end{array}$ & $\begin{array}{l}98 \\
56 \\
84 \\
84\end{array}$ & $\begin{array}{l}91 \\
56 \\
77 \\
84\end{array}$ & $\begin{array}{l}89 \\
49 \\
70 \\
76\end{array}$ & $\begin{array}{l}84 \\
40 \\
65 \\
56\end{array}$ & $\begin{array}{l}\text { Too high } \\
\text { Too low } \\
\text { Too much hemispheric asymmetry, too high } \\
\text { Too much hemispheric gradient, too high }\end{array}$ \\
\hline T5 & Tropospheric $\begin{array}{c}\mathrm{K}_{\mathrm{zz}}=3 \\
\theta<0^{\circ}\end{array}$ & 84 & 70 & 70 & 63 & Too much hemispheric gradient, too high \\
\hline T6 & $\begin{array}{c}v_{S}=v_{N}=4 \times 10^{-3} \mathrm{~cm}^{2} \mathrm{~s}^{-1} \\
\text { Tropospheric } K_{\mathrm{yy}}=3 \times 10^{10} \mathrm{~cm} \mathrm{~s}^{-1}\end{array}$ & 70 & 69 & 65 & 61 & Marginal \\
\hline $\begin{array}{l}\text { Standard Model } \\
\text { Observation }\end{array}$ & & $\begin{array}{l}67 \\
65\end{array}$ & $\begin{array}{l}67 \\
66\end{array}$ & $\begin{array}{l}59 \\
59\end{array}$ & $\begin{array}{l}58 \\
59\end{array}$ & Johnston (1988) \\
\hline
\end{tabular}

All model parameters are the same as in the standard model except otherwise stated. For comparison, the deposition velocities in the standard model are $v_{S}=3 \times 10^{-3} \mathrm{~cm} \mathrm{~s}^{-1}$ and $v_{N}=5 \times 10^{-3} \mathrm{~cm} \mathrm{~s}^{-1}$ in the southern and northern hemisphere, respectively. Tropospheric values of excess ${ }^{14} \mathrm{C}$ at $5 \mathrm{~km}$ are given for $70^{\circ} \mathrm{N}, 31^{\circ} \mathrm{N}, 9^{\circ} \mathrm{N}$, and $42^{\circ} \mathrm{S}$ in January, 1966. For comparison, the observed values at this time, and the results of the standard model are presented in the last rows.

are chosen in the standard model. The most puzzling conclusion is the hemispheric asymmetry of $v_{S}$ and $v_{N}$, which is opposite to what is expected if the oceans are the major sink for ${ }^{14} \mathrm{C}$ [Lal and Suess, 1968]. If our conclusion is verified, it will have a profound implication for the global carbon budget. Further work is obviously necessary to assess the quality of the tropospheric data, and to improve the tropospheric transport in our model.

\section{CONCLUSIONS}

We have studied the distribution of excess ${ }^{14} \mathrm{C}$ from $\mathrm{OC}$ tober, 1963 to December, 1966 using our two-dimensional model with transport coefficients taken from Yang and Tung [1989]. The model successfully accounts for the observations (Johnston, 1988). Excess ${ }^{14} \mathrm{C}$ is a unique tracer of atmospheric motion because it is derived from an impulsive source, and because it has initially large spatial gradients. Useful limits on the stream function and horizontal eddy diffusivity are obtained for the lower stratosphere as summarized in Table 2. We show that the data require a variable $K_{y y}$ which is smaller in the tropics and larger at higher latitudes, consistent with the predictions of Yang and Tung [1989]. This is the first time that excess ${ }^{14} \mathrm{C}$ has been modeled from its source in the stratosphere to its ultimate sink on the surface. The deposition velocities, empirically derived in this study, are generally consistent with the rate of exchange between the atmosphere and the ocean, although a slight asymmetry between the hemispheres is puzzling (see Table 3). This opens up an exciting possibility of tracing the ultimate fate of excess ${ }^{14} \mathrm{C}$ to its biospheric sinks on land and in the oceans.

Acknowledgments. We thank K. K. Tung and H. Yang for sending us the detailed transport coefficients of their two-dimensional model and for many discussions and comments which resulted in a great improvement of this paper. We are indebted to $H$. $S$. Johnston and F. S. Rowland for useful discussions. An anonymous referee was helpful in sharpening the conclusions of our paper. This work is supported by NASA grant NAGW-413 to the California Institute of Technology. Contribution 4724 from the Division of Geological and Planetary Sciences, California Institute of Technology.

\section{REFERENCES}

Brewer, A. W., Evidence for a world circulation provided by the measurements of helium and water vapor distribution in the stratosphere, Q. J. R. Meterol. Soc., 75, 351-363, 1949.

Broecker, W. S., and T.-H. Peng, Tracers in the Sea, Eldigio Press, New York, 1982.

Dobson, G. M. B., Origin of polyatomic molecules in the atmosphere, Proc. R. Soc. London, Ser. A, 236, 187-193, 1956.

Edmon, H. J., Jr., B. J. Hoskins, and M. E. McIntyre, EliassenPalm cross sections for the troposphere, J. Atmos. Sci., 97, 2600 2616, 1980. (Corrigendum, J. Atmos. Sci., 98, 1115, 1981.)

Froidevaux, L., M. Allen, and Y. L. Yung, A critical analysis of $\mathrm{ClO}$ and $\mathrm{O}_{3}$ in the mid-latitude stratosphere, J. Geophys. Res., 90, 12,999-13029, 1985.

Garcia, R. R., and S. Solomon, A numerical model of the zonally averaged dynamical and chemical structure of the middle atmosphere, J. Geophys. Res., 88, 1379-1400, 1983.

Geller, M. A., and M. F. Wu, Troposphere-stratosphere general circulation statistics, in Transport Processes in the Middle Atmosphere, edited by G. Visconti and R. R. Garcia, D. Reidel, Hingham, Mass., 1987.

Guthrie, P. D., C. H. Jackman, J. R. Herman, and C. J. McQuillan, A diabatic circulation experiment in a two-dimensional photochemical model, J. Geophys. Res., 89, 9589-9602, 1984.

Holton, J. R., Meridional distribution of stratospheric trace constituents, J. Atmos. Sci., 49, 1238-1242, 1986.

Johnston, H. S., D. Kattenhorn, and G. Whitten, Use of excess carbon 14 data to calibrate models of stratospheric ozone depletion by supersonic transports, J. Geophys. Res., 81, 368-380, 1976.

Ko, M. K. W., K. K. Tung, D. K. Weisenstein, and N. D. Sze, A zonal mean model of stratospheric tracer transport in isentropic coordinates: Numerical simulations for nitrous oxide and nitric acid, J. Geophys. Res., 90, 2313-2329, 1985.

Ko, M. K. W., M. B. McElroy, D. K. Weisenstein, and N. D. Sze, Lightning: A possible source of stratospheric odd nitrogen, $J$. Geophys. Res., 91, 5395-5404, 1986.

Lal, D., and H. E. Suess, The radioactivity of the atmosphere and hydrosphere, Annu. Rev. Nucl. Sci. 18, 407-434, 1968.

Leovy, C. B., Simple models of thermally driven mesospheric circulations, J. Atmos. Sci., 21, 327-341, 1964.

Liss, P. S., Tracer of air-sea gas exchange, Philos. Thans. R. Soc. London, Ser. A, 325, 93-103, 1988.

List, R. J., and K. Telegadas, Using radioactive tracers to develop a model of the circulation of the stratosphere, J. Atmos. Sci., 26, 1128-1136, 1969.

Mahlman, J. D., Relation of stratospheric-tropospheric mass exchange mechanism to surface radioactivity peaks, Arch. Meteorol. Geophys. Bioklimatol., Ser. A., 15, 1-25, 1965.

Murgatroyd, R. J., and F. Singleton, Possible meridional circu- 
lations in the stratosphere and mesosphere, Q. J. R. Meteorol. Soc., 87, 125-135, 1961.

Newman, P. A., M. R. Schoeberl, and R. A. Plumb, Horizontal mixing coefficients for two-dimensional chemical models calculated from National Meteorological Center data, J. Geophys. Res., 91, 7919-7924, 1986.

Newman, P. A., M. R. Schoeberl, R. A. Plumb, and J. E. Rosenfield, Mixing rates calculated from potential vorticity, J. Geophys. Res., 99, 5221-5240, 1988.

Pinto, J. P., Y. L. Yung, D. Rind, G. R. Russell, J. A. Lerner, J. E. Hansen, and S. Hameed, A general circulation model study of atmospheric carbon monoxide, J. Geophys. Res., 88, 3691-3702, 1983.

Pitari, G., and G. Visconti, Two-dimensional tracer transport Derivation of residual mean circulation and eddy transport tensor from a three-dimensional model data set, J. Geophys. Res. 90, 8019-8032, 1985.

Plumb, R. A., and J. D. Mahlman, The zonally averaged trans port characteristics of the GFDL general circulation/transport model, J. Atmos. Sci, 44, 298-327, 1987.

Prather, M. J., Numerical advection by conservation of secondorder moments, J. Geophys. Res., 91, 6671-6681, 1986.

Reed, R. J., and K. E. German, A contribution to the problem of stratospheric diffusion by large-scale mixing, Mon Weather Rev., 93, 313-321, 1965.

Reiter, E. R., Stratospheric-tropospheric exchange processes, Rev. Geophys. Space Phys., 19, 459-474, 1975.

Stordal, F., I. S. A. Isaksen, and K. Horntveth, A diabatic circular tion two-dimensional model with photochemistry: Simulation of ozone and long-lived tracers with surface sources, J. Geophys. Res., 90, 5757-5776, 1985.
Tung, K. K., On the two-dimensional transport of stratospheric trace gases in isentropic coordinates, J. Atmos. Sci., 39, 23302355, 1982.

Tung, K. K., Modeling of tracer transport in the middle atmosphere, in Dymamics of the Middle Atmosphere, edited by J. R. Holton and T. Matsuno, pp. 417-444, Terra, Tokyo, 1984.

Tung, K. K., Nongeostrophic theory of zonally averaged circula tion. Part I: Formulation, J. Atmos. Sci., 48, 2600-2618, 1986.

Tung, K. K., A coupled model of zonally averaged dynamics, radiation and chemistry, in Thansport Processes in the Middle Atmosphene, edited by G. Visconti and R. Garcia, D. Reidel, Hingham, Mass., 1987.

Tung, K. K., and H. Yang, Dynamical component of seasonal and year-to-year changes in Antarctic and global ozone, J. Geophys. Res., 93, 12537-12559, 1988.

World Meteorological Organization, Atmospheric Ozone 1985: Assessment of Our Understanding of the Processes Controlling its Present Distribution and Change, Rep. 16, Global Ozone Res. and Monit. Proj., Geneva, 1985.

Yang, H., and K. K. Tung, Non-geostrophic theory of zonally averaged circulation, II, Eliassen-Palm flux divergence and isentropic mixing coefficients, J. Atmos. Sci, in press, 1989.

M. Allen, D. Crisp, R.-L. Shia, Y. L. Yung, and R. M. Zurek, Division of Geological and Planetary Sciences, California Institute of Technology, Pasadena, CA 91125.

(Received December 14, 1988; revised April 19, 1989; accepted April 19, 1989.) 